Haviland, $\mathrm{Z}$ time, pg. 1

\title{
“But you said 'four sheep' ...!": (sign) language, ideology, and self (esteem) across generations in a Mayan family
}

John Haviland ${ }^{a}$

a Department of Anthropology, University of California, San Diego, 9500 Gilman Drive \#0532, La Jolla, CA 92093, United States of America, jhaviland@ucsd.edu.

\section{Introduction}

For the past few years I have been studying the manual communication system in a single household in highland Chiapas, Mexico, dubbed "Zinacantec family Homesign" or "Z" for short. The township of Zinacantán is a heavily studied (for example, Vogt 1969, 1976; Laughlin 1975, G. Collier 1975; J. Collier 1976; Cancian 1965, 1972, 1994; Haviland 1977) largely "indigenous" community where nearly everyone speaks Tzotzil (Mayan) as a first language. Formerly peasant corn-farmers and itinerant traders, some Zinacantecs over the past half century have become bilingual or at least well educated in Spanish and have moved into professions or entrepreneurial activities (from teaching, to large and small scale flower or agricultural farming, to transport or trade in everything from vegetables to acrylic yarns and patent medicines). When I first began ethnographic work in Chiapas, half a century ago, the community was determinedly monolingual in Tzotzil, although the oldest men in the township were the most likely to speak Spanish--often ungrammatical but prolific in obscenities--because their erstwhile work as muleteers had brought them into more intimate contact with ladinos (non-Indians) than did their sons' almost exclusive economic reliance on milpa cultivation at mid century. (Similarly, some elderly ladinos in San Cristóbal, especially those who relied on trade with Indians, could once speak passable commercial Tzotzil, something now unheard of among nonIndian Mexicans.) Nowadays in Zinacantán it is teenagers and young adults who are most likely to trade text messages in Spanish, although some lament that they never learned to write in Tzotzil, which would be more useful as a private code. ${ }^{1}$ Although there once used to be a significant number of Spanish speaking residents in the township, culturally non-Indian but with kinship and commercial links to the community, and bilingual in Tzotzil, almost all of these people have now left Zinacantán. Now only a few individuals remain in the township--most notably ladina wives who have moved into their Zinacantec husbands' homes-who are effectively monolingual in Spanish.

Adding an emergent "homesign" system (Goldin-Meadow 2003) like " $Z$ " to the language mix complicates matters, most notably by adding a third layer of potential linguistic difference

\footnotetext{
${ }^{1}$ While composing this essay, sitting at a desk in Italy in the summer of 2015 , I received an email message in Spanish from a San Cristóbal lawyer who introduced himself as a grandson of the senior musician from whom I had learned to play traditional Zinacantec music 49 years before. When I replied to him in Tzotzil he excused himself, saying that while he was fluent in both languages, he felt incompetent to communicate in writing in anything but Spanish.
} 
to the community. In addition to Tzotzil monolinguals, those who also speak Spanish, and the few Spanish monolinguals, there are-at least in the tiny social world of the $Z$ household--also deaf signers who speak no Tzotzil, and a few hearing signers fluent in both $Z$ and Tzotzil. In terms of size alone, but also given how they are represented in individuals' repertoires as well as the presumed attribution of different sorts of value to these linguistic varieties-evidence for which I present in this chapter--we can provisionally arrange these different languages by rank, ${ }^{2}$ as follows: $Z<$ Tzotzil < Spanish. Refining this crude scale against the actual complex linguistic trajectories of individuals, and calibrating it both with respect to the social selves speakers project (or have projected upon them), and against different time scales - that of an entire language, the lifespans of individuals, and the embedded temporalities of individual sign forms themselves - will be the main tasks of this essay.

Talk of "values" and "ranks" for languages is, of course, ideological talk, and it does not square well with the standard lessons one imparts to fledgling linguists about the ultimate equivalence of even the most "exotic" and endangered languages. The tenor of most academic research on emerging sign languages-like that of sign linguistics in general-has an even stronger polemic: to show that even relatively young sign languages display (or move quickly towards) certain familiar kinds of linguistic structure: parts of speech (see, for example, Haviland 2015b), morphosyntax, and duality of patterning, among others. As a researcher one often feels compelled to de-emphasize difference or limitation, and to assert comparability and complexity even in a first-generation sign language like Z: to show, that is, that $Z$ is a language. Nonetheless, our researchers' prejudices against attributing differential values to languages stand in obvious conflict with ubiquitous and undeniable local social valuations. However much we might argue that Tzotzil, for example, displays complex synthetic morphology, ergative syntax, and delicate semantic partitioning of different denotational domains, or that its developed speech genres rival the richness of any literary tradition, or that it equips its most masterful speakers with rhetorical skills that would be the envy of any Western politician, it remains a perhaps sad fact that in many situations Tzotzil speakers readily abandon the language in favor of Spanish (or, when immigrating to the United States, English). In the present case, as we shall see, the hearing members of the signing Z family hardly imagine that signing enriches the lives of those who should also be able to learn to speak. (In fact, they find curious and a bit comical my obsessive linguist's interest in Z, which they sometimes characterize as merely a system for $a k^{\prime}$ 'el iluk 'showing' rather than $k^{\prime}$ opojel 'speaking' or alel 'saying.')

The values and stigmas associated with specific linguistic varieties accrue ideologically to individuals who manifest them in their communicative repertoires; moreover, familiar properties of such language ideologies (Gal \& Irvine 2000) imply that languages, whether spoken or signed, project onto individuals associated with them other, parallel scales of value, including--in the case of Z--scales of personhood and social age. In this essay I step back from

\footnotetext{
${ }^{2}$ I thank the editors for suggesting that I make explicit such a scale.
} 
my own ideology as a linguist who concentrates on the undeniable details of $Z$ linguistic structure, to reflect ethnographically on the preoccupations, attitudes, and decisions that shape what it means to be a Z signer in the community itself.

After introducing the full--if tiny--Z speech (i.e., sign) community, I concentrate on the signing of the first deaf person in the extended family and then turn to the single fluent second generation signer, her hearing son. How has he been socialized into language, and what sort of person is he as a result? How is this consequentially different from the situation of his mother? I rely on aspects of directed acquisition to adduce evidence for nascent linguistic norms, or standards of well-formedness, in the emerging sign language-that is, in part, to show that $Z$ is, indeed, formally a language in the received sense. The phenomena I present are thus intended to help us reflect on the biographical, sociological, and corporeal bases of creating a language, as it were, out of thin air. More pertinent for the present collection, I consider how linguistic interventions and interactions among signers, and between caregivers and child, shape not only signers' linguistic abilities but also their senses of what kind of (communicating) persons they are, contrasting the case of the bilingual child as he grows into language with that of his monolingual signing mother, the first and for several years the only deaf person in the family.

\section{Z}

Fig. 1 shows an abbreviated genealogy of the community of $Z$ signers, including the three deaf siblings, their hearing sister, and several further hearing native signing nephews and nieces who grew up in this extended household with $Z$ and spoken Tzotzil as their means of communication. $Z$ has emerged with no input from other sign languages or deaf people. Vic, son of Jane, the first signer, is the child whose growing linguistic capacities and sense(s) of self are, along with those of his mother, the main focus of this essay.

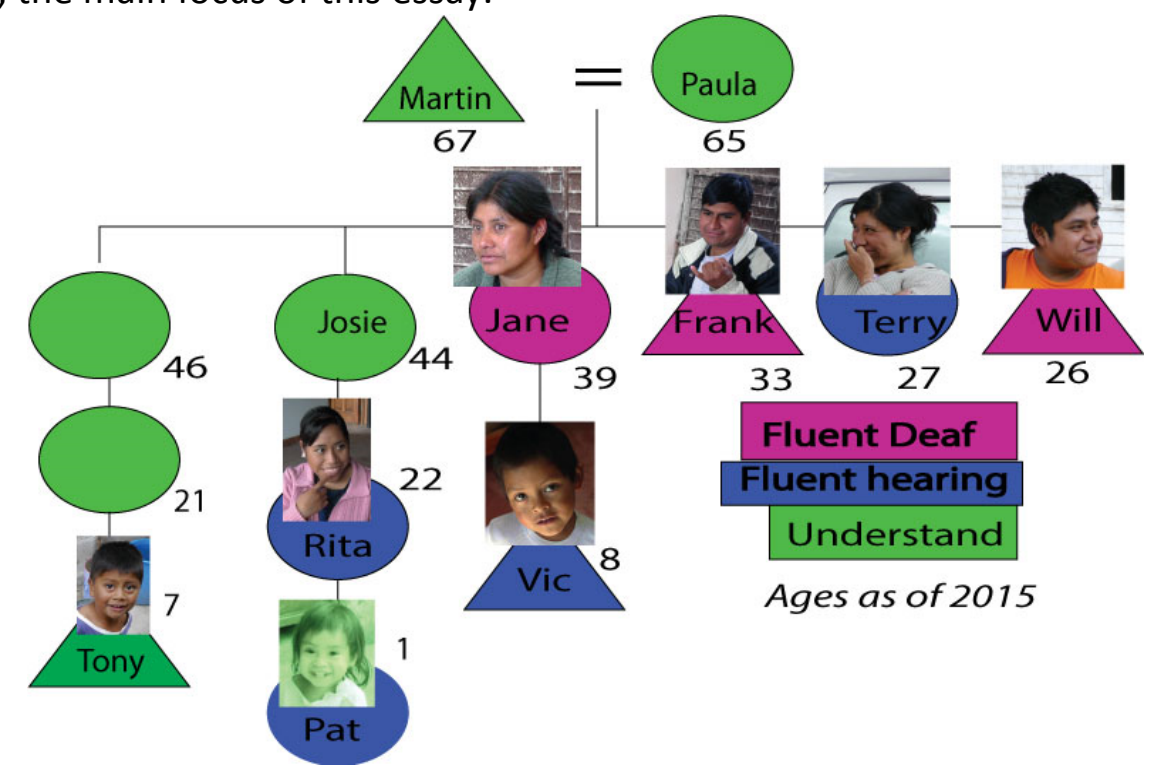

Fig. 1. Abbreviated genealogy of $Z$ signer community. 
Consider the sort of linguistic experience Jane must have had, as the only deaf person in her household (and, indeed, in her entire village) for the first 6 years of her life, with no direct access to any language system. Contrast this with the language learning experience of her son Vic, born with normal hearing thirty years later into a household where, at least at first, his caregivers communicated with him by preference in the already emerging family homesign, as well as in spoken Tzotzil. What sorts of conceptual tools and categories did Jane develop as she interacted with the world around her? How did she come to understand her own communicative abilities and, consequently, her place in the world? Part of what both Jane and Vic clearly had available to work with was the system of speaker's gesture prominently displayed when Zinacantecs talk. But how different those same resources must have been for Jane as opposed to Vic! It is partly the different time scales implied by these contrasts that I mean to explore in this essay: the difference between being a lone first speaker vs. a learner in a speech community, and between having power over fashions of speaking (by being able to adapt and change them in consequential ways) vs. being held in their thrall. My ironic conclusion will be that Jane, the oldest and original signer, is the individual most trapped in the language, whereas her son Vic, possibly the very last fluent $Z$ signer, is in important ways freed of its constraints and those of the miniature community in which it is embedded.

\subsection{Fashions of signing: Jane}

In a previous publication (Haviland 2013), I took $Z$ as an almost limiting case of a speech community, at the miniature end of the scale, where language variation reflects internal social divisions. The leading example was how Jane signs 'chicken.' Virtually all of the other $Z$ signers normally perform 'chicken' by combining what, in sign language linguistics, is often called a "size and shape specifier" (or SASS) with a nominal "characterizing sign" based on a characteristic related action. The first element illustrates the physical dimensions of a nominal referent by showing in a stylized way how the object in question is held and handled. Fig. 2 shows Will signing 'rooster,' starting with the SASS. He goes on to perform the conventional Z characterizer for 'chicken,' a pantomimic enactment which illustrates the quick jerk by which Zinacantecs normally kill such domestic fowl (Fig. 3).

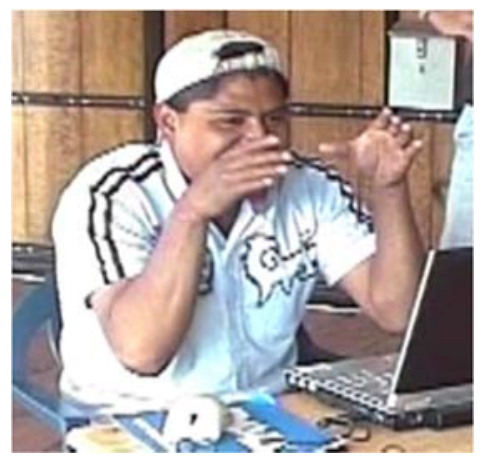

Fig. 2. Will initiating the sign for 'rooster' using the SASS. 


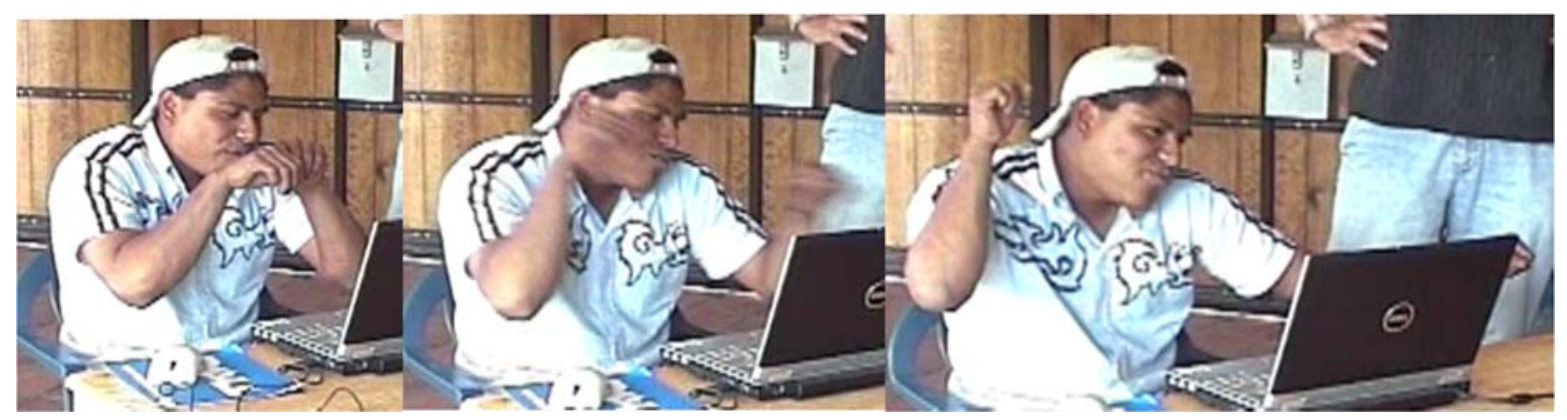

Fig. 3. Will performing the conventional Z characterizer for 'chicken.'

By contrast, Jane almost always spontaneously signs 'chicken' by using just the SASS, as for example in Fig. 4, taken from a long narrative in which Jane is telling her sisters that a chicken-which she mentions here for the first time--has eaten some vegetables planted at home (see Haviland 2014). Such performances normally generate neither misunderstanding nor comment: the other signers, on this occasion, unambiguously interpreted Jane to be talking about a chicken.

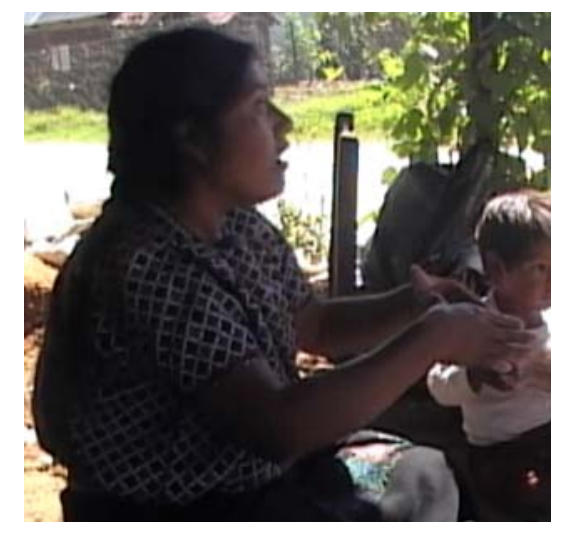

Fig. 4. Jane signing 'chicken' using the SASS.

Following familiar axioms of historical linguistics, the language-internal contrast between Jane's signing and that of the younger signers suggests an instance of grammatical development in Z where Jane's presumed early efforts at communicating about common objects primarily employed (proto)SASS elements. Over time these SASS signs appear to have been gradually supplemented by characterizing elements, at least in the signing of her younger brothers. One can speculate that one of Jane's early "nouns" might have been 'chicken,' given the important role of the birds in the domestic economy into which she was socialized as a little girl. A lone SASS might generally have been referentially adequate, at least in a given speech context, in Jane's early productions, although one imagines that as the inventory of possible "nouns" increased, further specification-sometimes in the form of added characterizing enactments-emerged, leading to an expanded syntagm for nominal referents of the form SASS+Characterizer. There is, in other words, a time frame embedded in the sign form: Jane's 
habitual signing indexes an earlier moment in (developmental) time than that of her brothers; it also indexes her both as older than they chronologically, and, notably, as more childlike in her signing insofar as her habitual signing reflects what would have been an earlier form in the signing of her brothers.

I should emphasize that Jane's apparently simpler signing is by itself evidence of neither referential nor linguistic deficiency. As to the former, I have only rarely seen her interlocutors misunderstand her when she refers to a chicken with just a SASS. The other signers know that, other things being equal, this is how she does it. In her "ideolect," that is, the bare SASS is recognizable as her sign for 'chicken.' Nor is it the case, as regards "deficiency," that she simply lacks the more elaborated form. Consider, for example, the following sequence, drawn from a description of a photograph in which two cats are staring out of a window with a small chicken standing outside. Jane signs 'cat,' and 'try/want to eat'; she then signs a "full" chicken clause, complete with SASS (Fig. 5), a rapid neck-jerk characterizer (Fig. 6-note that Jane performs the motion downwards rather than sideways), and a "verb" (Fig. 7). The whole utterance can be glossed as "A chicken is looking inside/toward the viewer." The example suggests that when clarifying argument structure, or differentiating multiple possible participants in an event, Jane is perfectly able to distinguish among various nominal constituents by adding a characterizer to a SASS, despite the fact that she routinely does not bother to do so (at least when referring to chickens).

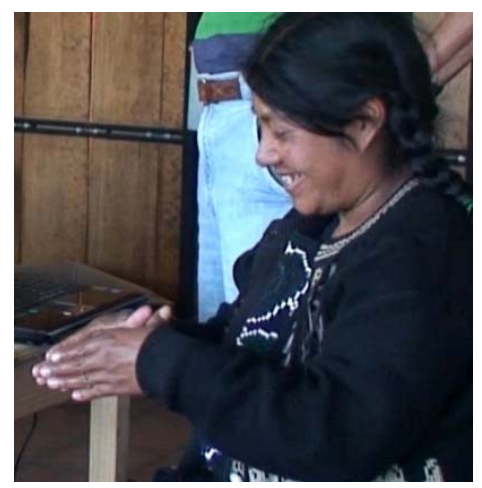

Fig. 5. Jane using the SASS for 'chicken.' 


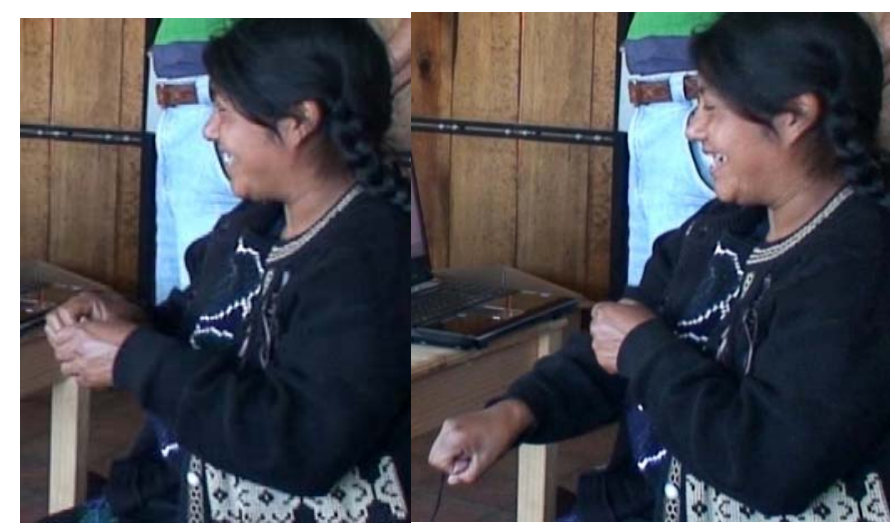

Fig. 6. Jane continuing the sign with the conventional $Z$ characterizer.

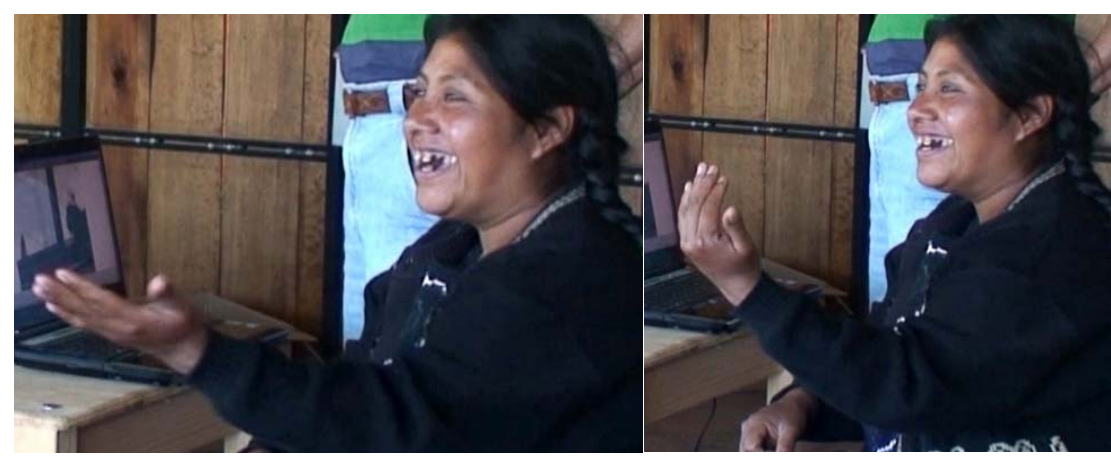

Fig. 7. Jane adding the verb 'looking this way' to the utterance.

Nonetheless, Jane sometime suffers severe criticism from her brothers for her signing, especially in the competitive picture matching tasks I routinely subject the signers to as an elicitation technique. For example, describing a scene where a single chicken is scratching for food among corn cobs strewn on the ground, Jane used just a SASS (Fig. 8), followed by signs depicting the chicken standing and scratching, then the sign for corn on the cob (Fig. 9), and finally repeating the initial SASS (Fig. 10).

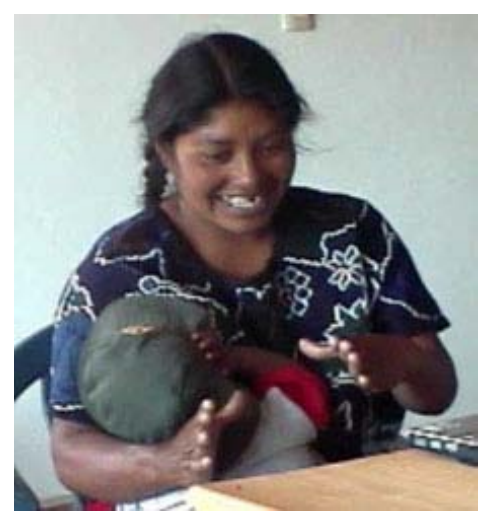

Fig. 8. Jane signing the SASS for 'chicken.' 
Haviland, $\mathrm{Z}$ time, pg. 8

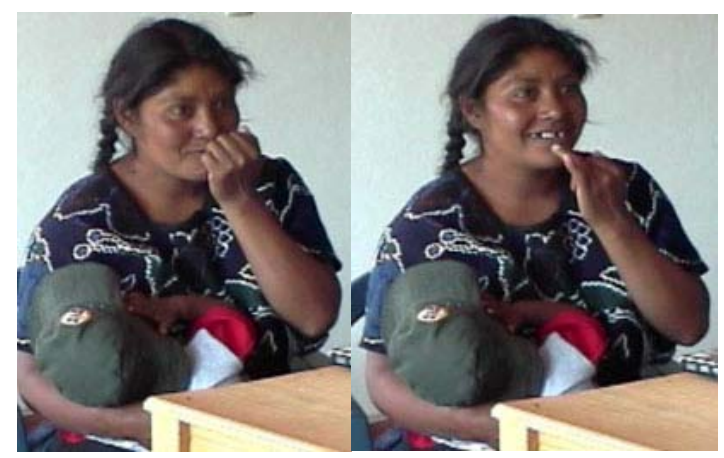

Fig. 9. Signing 'corn cob'

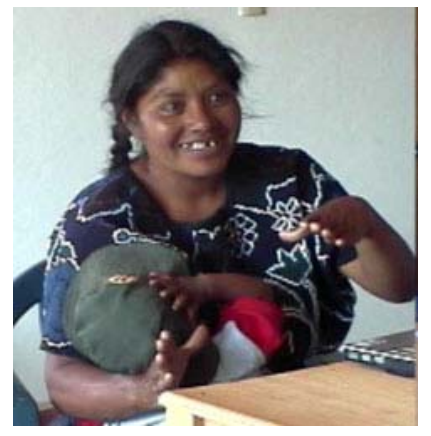

Fig. 10. Repeating the initial SASS.

If one understands Jane's signs at Fig. 8 and Fig. 10 as her conventional lexeme for 'chicken' rather than (or as well as) a more general SASS, the denotational content of her description seems reasonably clear: "a chicken, standing, with corncobs on the ground." However, on this occasion and quite exceptionally, her brothers had a hard time finding a matching picture. Looking more broadly at the eliciting situation, it is not hard to see why the correct photo might have been difficult to pick out. The stimulus pictures on this day were mixed snapshots taken around the $Z$ signers' house compound, and they were deliberately arranged to make them challenging to identify: close-ups of small objects, articles of clothing, fruits and vegetables, furniture, assorted tools both whole and broken, a few animals, random objects hanging from walls or thrown on the ground, and so on. The shots were neither carefully framed nor wellcomposed, and they thus often included multiple namable items, partly to encourage effusive signed descriptions, but also making them potentially confusing. 
In any case, Frank and Will demanded clarification. Jane provided it, starting this time not with the chicken but with 'corncob' and 'thrown on the ground' (since, in fact, these items were in the center of the photograph to be described-see Fig. 21). She only then repeated her SASS for 'chicken' (Fig. 11) and a sign for 'walking.'

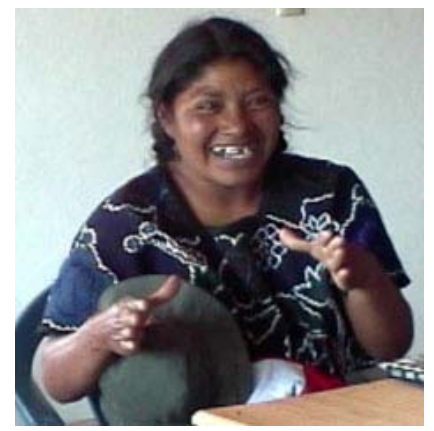

Fig. 11. Jane repeating the SASS for 'chicken' again.

After considerable discussion, the brothers ultimately figured out which picture Jane meant, but their reaction was demonstratively critical and dismissive. Will aimed an accusatory finger at Jane, while Frank, with escalating apparent grumpiness, presented her with ever more insistent "corrected" formulations (Fig. 12 \&Fig. 13).

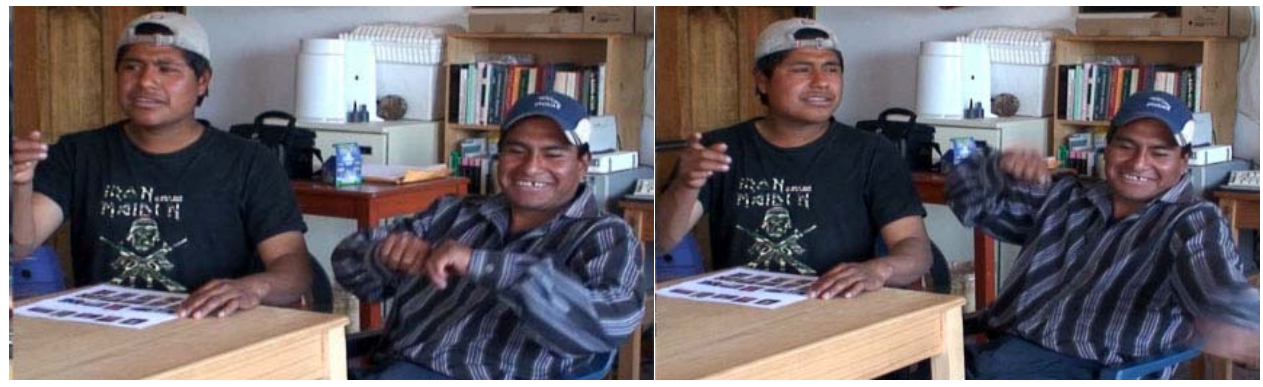

Fig. 12. Will and Frank expressing annoyance at and re-phrasing Jane's signing.

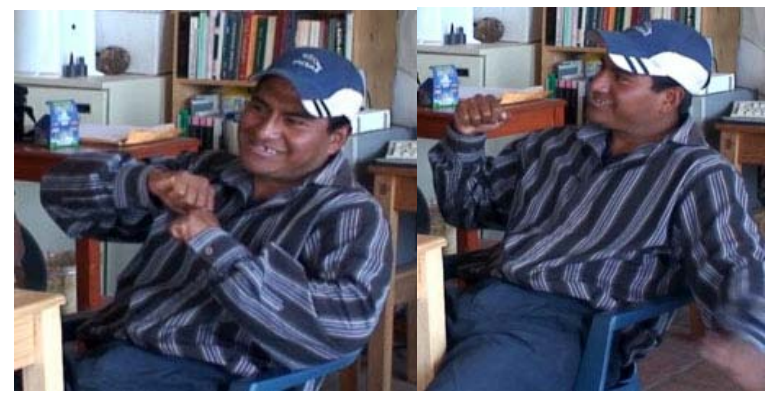

Fig. 13. Frank showing Jane the "corrected" signs.

Frank ended his metalinguistic tantrum with a power-laden affective performance, directing an extremely annoyed look at Jane (Fig. 14), demonstrating an even more exaggerated neck-jerk (Fig. 15), then sharing his dissatisfaction over Jane's signing with a grimace to his by-stander sister Terry (Fig. 16) and a final head shake, eyes closed in exasperation. (Terry, the hearing 
sister of the deaf siblings, who was the first person to be fluent in both $\mathrm{Z}$ and Tzotzil, is a prominent background protagonist and interlocutor in what follows, although she does not appear in any of the illustrations of signing.)

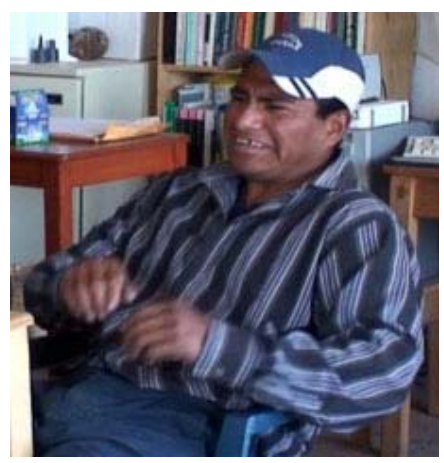

Fig. 14. Frank exhibiting his annoyance.

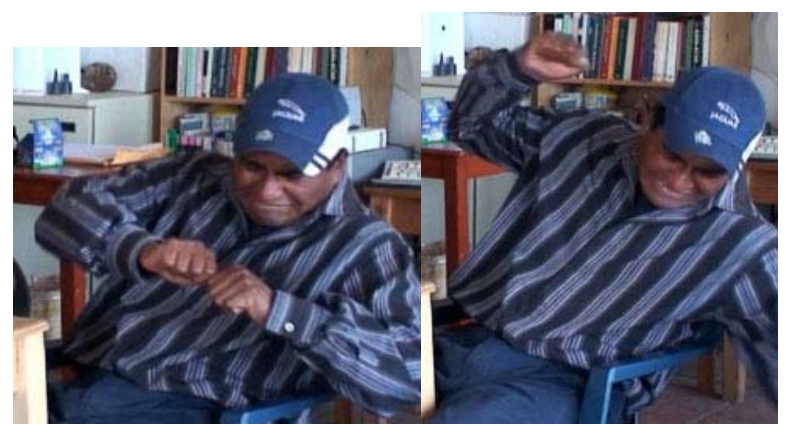

Fig. 15. Eggageratedly signing the neck jerk for 'chicken.'

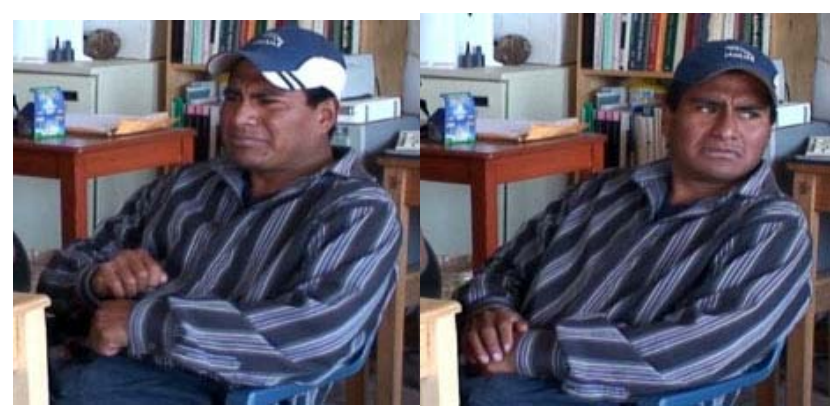

Fig. 16. Sharing a disapproving look with sister Terry.

In much the same way that the simpler noun phrase with just a SASS contrasts with the formally elaborated SASS+Characterizer version--corresponding both to a (supposed) ontogenetically prior versus a later epoch of invention, and also to a simpler vs. a more elaborated context of use-the interactive dynamic between sister and brothers also reveals a sociological and ideological asymmetry between speakers' "selves," interactively projected and thereby rendered socially observable and consequential. The brothers' openly and somewhat brutally critical stance toward Jane's signing suggests, on the one hand, their own confidence about how to sign "correctly," and, on the other, their construal of her different linguistic habits 
(and, by extension, her capacities more widely, communicative and otherwise) as inadequate, worthy of ridicule and (at least mimed) anger. Looking back on the entire eliciting session from which this example is drawn, I also intuit that part of Frank's exaggerated reaction to Jane's inadequate signing may also have come from the fact that, nearly an hour earlier in another part of the same eliciting session, Jane had already signed 'chicken' using just the SASS, and had received a much more good-natured criticism from Frank that she should have included the neck-jerk after the SASS.

How Jane herself feels in the face of her brothers' vitriolic scorn is harder to tell (and it is not easy to ask her directly). By carefully observing her reaction to Frank's apparently angry criticism shown in Fig. 14-Fig. 16 (dissected below with synchronized split screen images), we can gather indirect clues. She watches both brothers as they launch their first complaints (which are addressed to Terry, the hearing sister, who has been observing the conversation just off camera, having been instructed by me to give a running Tzotzil gloss on the signing as I work the video cameras in this semi-experimental eliciting context). Jane turns her gaze first to Will (Fig. 17) and then to Frank (Fig. 18) as they joke about her signing; she then looks back at Will as he complains that she signed 'corn-on-the-cob' (Fig. 19).

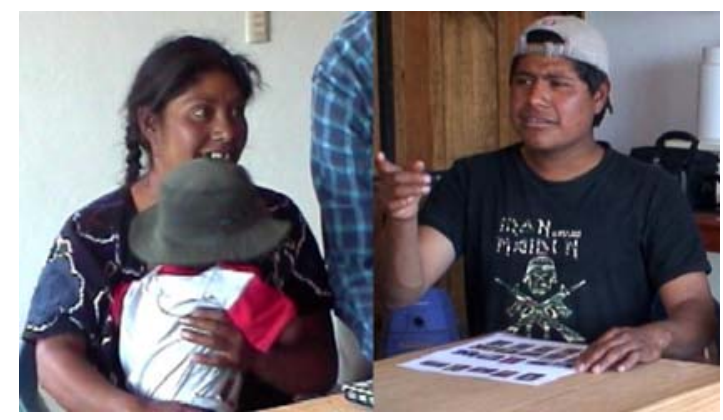

Fig. 17. Jane looking to Will for his reaction.

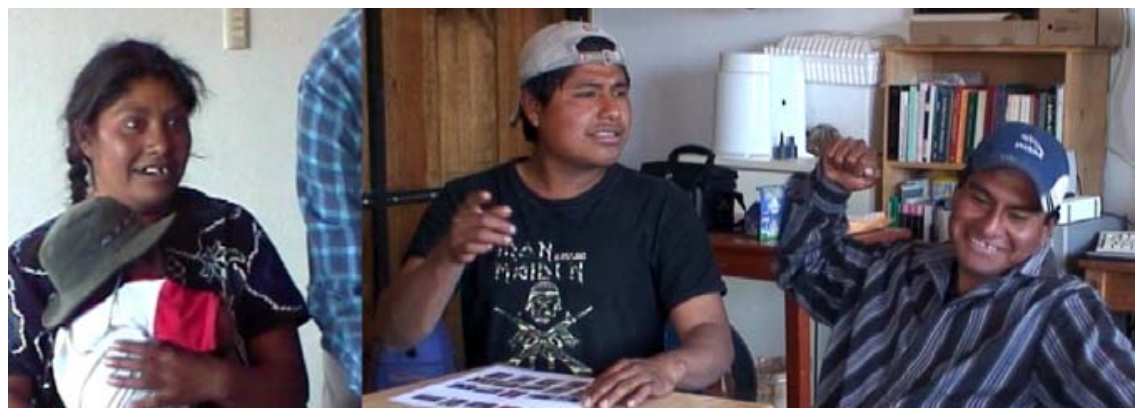

Fig. 18. Jane appearing taken aback at Will and Frank's reactions. 


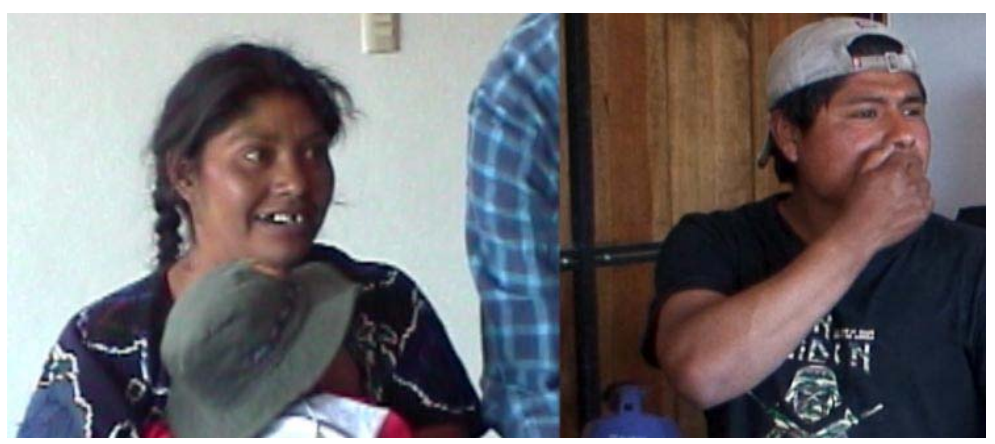

Fig. 19. Jane watching Will complain about her signing.

Against this last complaint, she retorts animatedly: "Yes! I said 'corn cob' because there are corn cobs strewn on the ground" (see Fig. 20). Notably, her defense against her brothers is about propositional content rather than sign form: the picture she is describing does, indeed, depict a chicken and corncobs (Fig. 21). Frank's original criticism, at Fig. 13 above, seems to have been instead about her incorrect sign form, which left the two brothers initially confused about the correct stimulus picture.

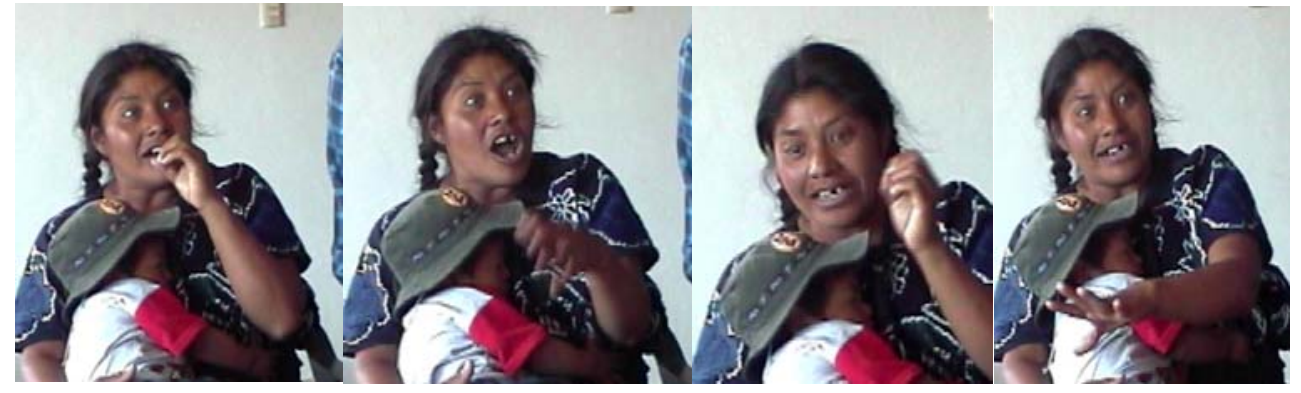

Fig. 20. Jane animatedly defending her signage.

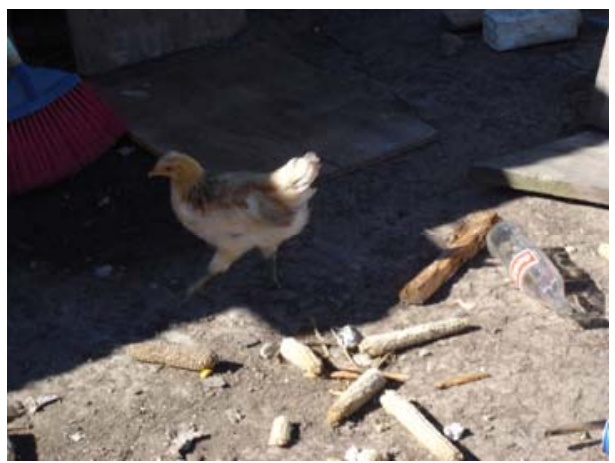

Fig. 21. Image depicting chicken and corncobs.

However, even as she starts to justify herself, Frank begins his angrily enunciated "you should sign 'chicken' like this," demonstrating the particularly violent neck-jerk shown above (Fig. 15). Frank's criticism rejects Jane's referential self-defense in favor of an affectively inflected argument about propriety in signing. Her reaction is highly revealing about how such a metalinguistic interaction shapes her self-representation as an intelligent, moral, and capable 
person. Jane greets Frank's angry and accusatory face (and Will's half-smile/half frown) with a somewhat abashed grin (Fig. 22).

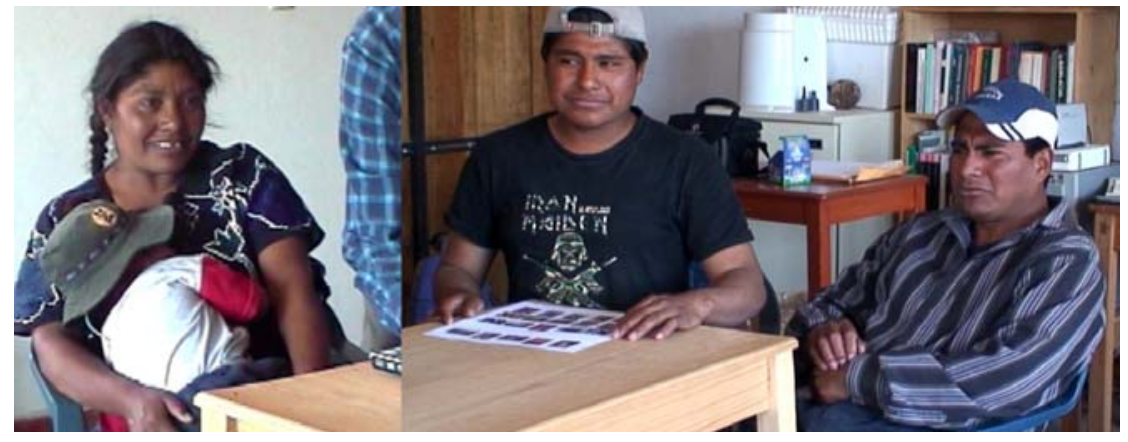

Fig. 22. Jane's response to her brothers' affronted expressions.

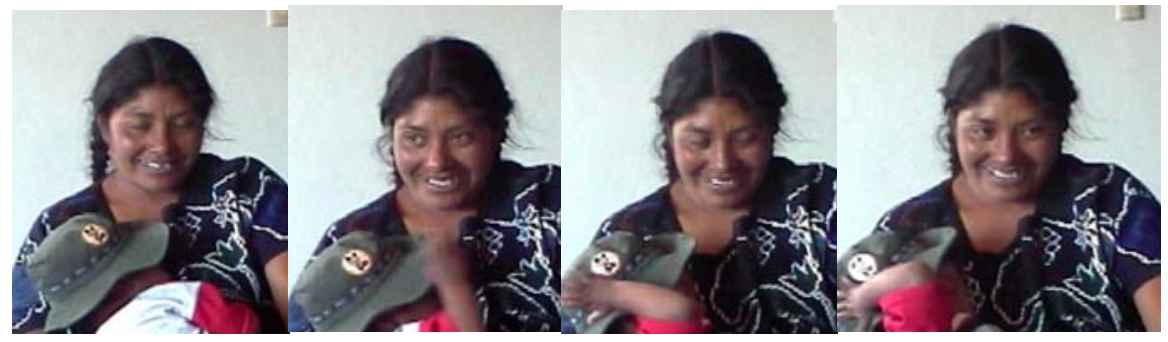

Fig. 23. Jane expressing embarrasment.

There follows a fleeting but eloquent full second (Fig. 23)--30 frames of the video--during which Jane avoids Frank's accusatory gaze, looking down and even closing her eyes (although she never quite loses her chagrined smile). To me, at least, the reaction suggests that she can offer no real defense against Frank's deontic "You should sign 'chicken' this way!" She recovers only by trying once more to justify the referential fidelity of her signed description, turning to her sister ${ }^{3}$ and again citing the corn cobs of the original stimulus picture (Fig. 21).

\footnotetext{
${ }^{3}$ Ben Smith, in comments, rightly intuits that there are important gender issues involved here: that Jane's susceptibility to criticism from her brothers (and their unabashed willingness to mete it out) reflect a gendered asymmetry of male-female power characteristic not only of this particular relationship but in Zinacantec interaction more widely; and that Jane may appeal to her sister Terry for support in her defense partly on the grounds of sisterly solidarity. Nonetheless, in this largely female dominated household matters are considerably more complex in ways that would take us well beyond the bounds of this essay.
} 
Haviland, $Z$ time, pg. 14

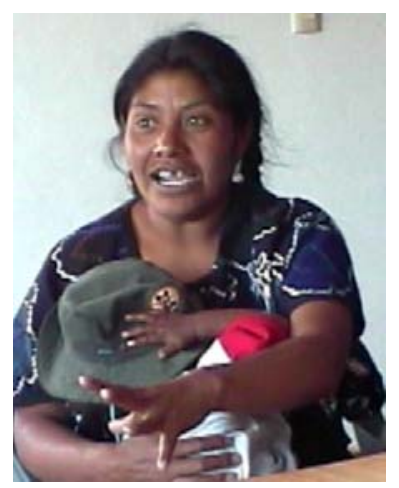

Fig. 24. Jane attempting to justify her signing to Terry.

Even though Jane is the oldest of the signers, and the vixil 'elder sister' (a kind of supplemental mother figure) to the other mukil 'younger sibling' adult signers, her preference for the lone SASS to denote 'chicken' is a symptomatic index of the "fashions of speaking/signing" that apparently mark her as indelibly incompetent relative to her siblings, chronologically older but intellectually far behind them (at least in their own opinion).

\subsection{The infant Vic}

Consider now the contrasting case of Vic, Jane's hearing son, who is the first-and perhaps also the last - of the nascent second generation of $Z$ signers. I have known all the $Z$ signers their whole lives, but it was not until Vic was born that I finally found the courage to undertake systematic study of their communicative repertoires. By this time, the deaf signers were all young adults, and I had missed the process by which Jane's homesign had been transformed into the shared language of the small cohort of family signers. The first time I was able to film young Vic, at 11 months of age, he was already well socialized into using his hands as visible communicative devices, partly by virtue of the fact that, like many infants, his gestures were routinely interpreted and acted upon. He had the same sorts of gestural routines that most babies have, reaching and pointing, for example, at desired objects. 
Well before he had started to talk (and when his grandparents were still worried about whether he ever would) Vic's communicative manual gestures were not only interpreted but also regimented via direct manipulation. For example, on the very first day that I filmed the adult signers, Jane brought Vic into the room where we were sitting, and he immediately started "asking" for a cup (or so he was understood). He made eye contact with his uncle Will and stretched out his arm towards a cup on the table in front of the two brothers (Fig. 25).

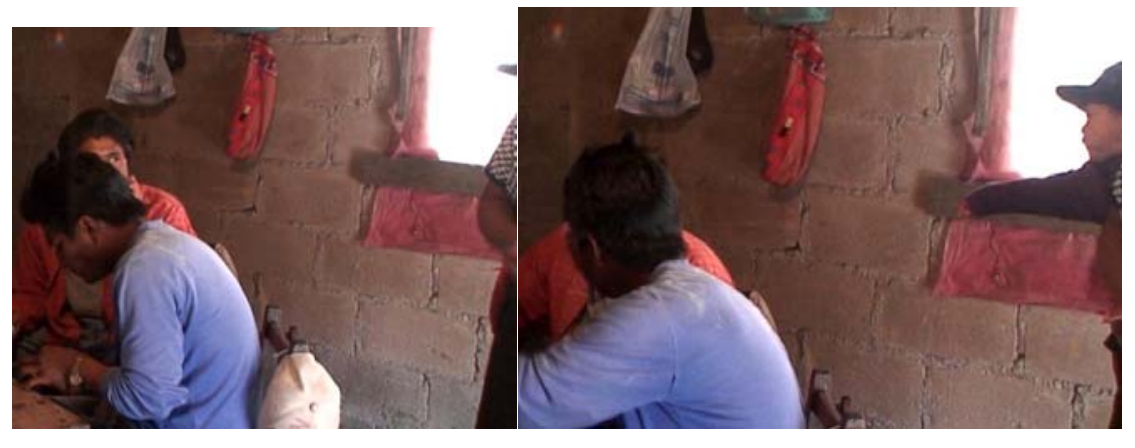

Fig. 25. Vic "asking" for a cup by reaching.

He repeated the gesture insistently, with accompanying vocalizations, until Jane ultimately suppressed the request, by taking his hand and pulling his arm down (Fig. 26), a manual equivalent of shushing him.

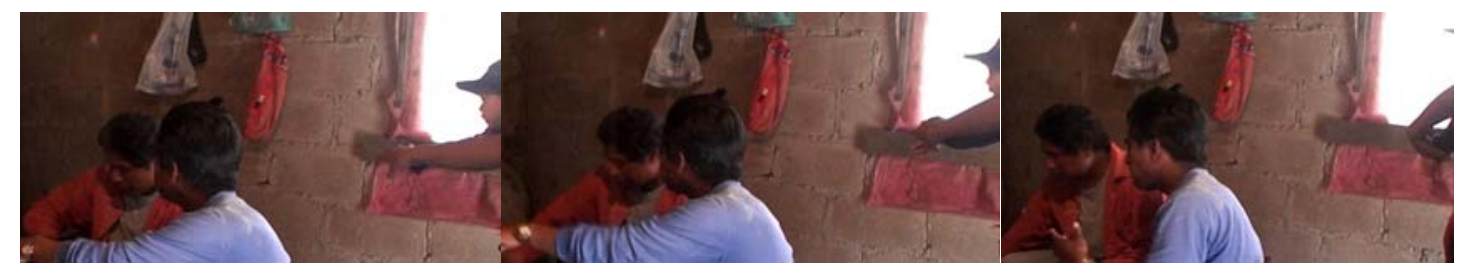

Fig. 26. Jane "shushing" Vic by pulling his arm down.

We can see in this tiny interaction the seeds of much that is to come: the fact that the infant's actions are taken, almost willy nilly, to embody intentional communication (with the complex chains of Gricean common ground and presupposition that "meaningnn" depends upon [Grice 1957]); the sense that mutual attention is required for this reading of action to obtain; and the fact that interactants have means (and, at least sometimes or in some circumstances, feel themselves entitled) to respond, reject, and alter the actions involved and their inferred communicative motives. This is obviously as true for gestured or signed actions as for spoken ones. Jane is able to tell Vic, by her action of pulling down his pointing hand, "Don't keep asking for that cup!" The elaborate feedback between interactants thus reinforces communicative acts and efficacy, as well as their-as it were-political economy. In Vic's case, such interactions give clear signals to him about what he can and cannot do, with whom, and, I would add, about what he is (taken to be) doing in the first place, and consequently who (that is, what sort of a person) he is. 
About one week before his first birthday, Vic was tied in a shawl on his aunt Terry's back when I filmed the signers in my first, abortive attempt at elicitation. Vic woke up in the middle of the session, and in his 1-year-old way, attempted to participate in the complex and lively interaction in the midst of which he found himself. He had learned to produce, at this point, virtually no spoken Tzotzil, but he immediately began to move his body in ways that all present took as attempts at signing in $\mathrm{Z}$, and about which they commented both cheerfully and critically. For example, he began to "point" with an outstretched index finger, seeking and meeting his interlocutor's gaze as he did so (Fig. 27).

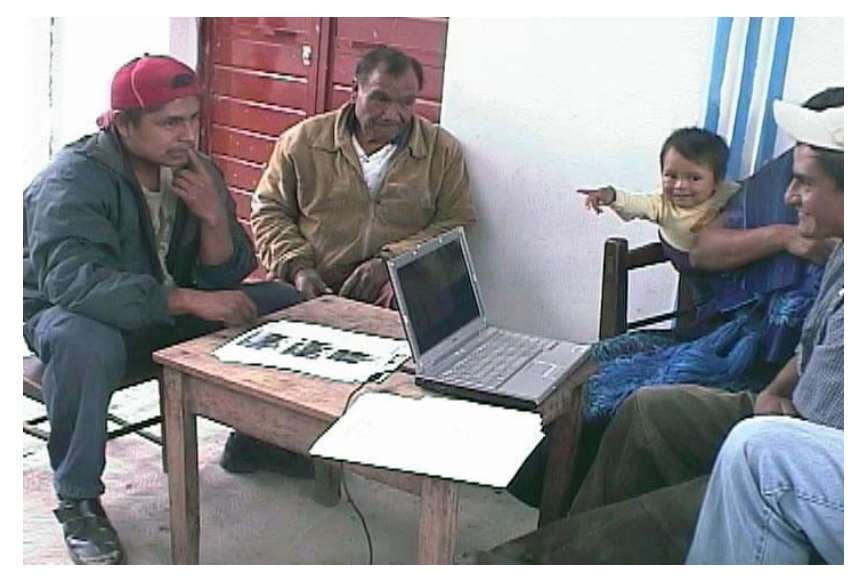

Fig. 27. Vic "pointing" in an attempt to participate in conversation.

He was also able to imitate (although it was hard to know at this stage whether he, as it were, "understood") the waving index finger that Tzotzil speakers and Z signers alike use as a multipurpose Negative marker (Fig. 28).

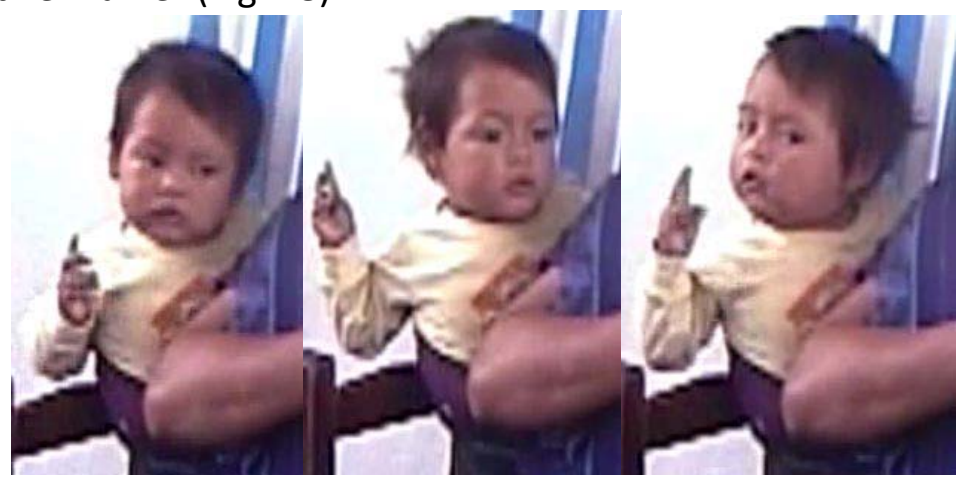

Fig. 28. Vic imitating the multipurpose Negative marker.

The adults greeted Vic's gestures with hilarity, but also with concern. As I hinted above, from the very moment he was born, there were concerns in the family about whether Vic would ever learn to speak or only to sign-a concern that had plagued every birth in the family since Jane's three decades earlier. The family's preoccupation reflected an attitude, rarely made explicit but always lurking in the shadows, that although via signing the deaf siblings were able to participate in important aspects of a normal Zinacantec life, truly speaking proper Tzotzil was vastly superior to signing. Vic's grandfather Martin took pains to point Vic's gestures 
out to others present (Fig. 29), addressing Vic in return with his own finger-wave, interpreted as an admonition to "keep quiet" (Fig. 30). ${ }^{4}$ What he says, turning to his wife, is:

$$
\text { s-k'op li k'ox uke }
$$

\section{A3-word ART child also ${ }^{5}$}

"The kid, too, is speaking" [uma080706aX 12:34.496].

Terry, on whose back Victor is tied, continues,

$$
\text { Ch-al uk }
$$

INC+A3-say also

"He's also saying [what the others are]."

His grandmother, Paula, agrees,

Ch-chan ch-av-äi

INC+A3-learn INC-A2-understand

"He wants to learn, don't you see?"

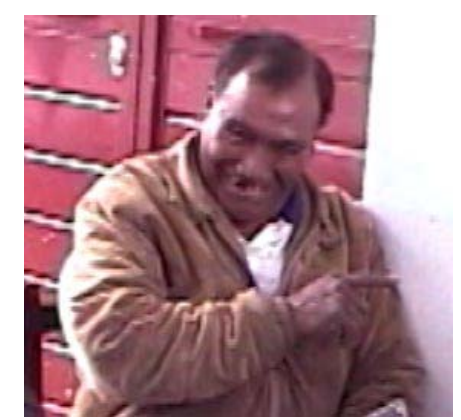

Fig. 29. Vic's grandfather Martin pointing out Vic's signing to the other adults.

\footnotetext{
${ }^{4}$ Martin is not himself a signer, and he has considerable difficulty understanding the deaf siblings when they sign, relying-much as I did at the beginning of my study of Z-on the hearing sister Terry to interpret for him. Similarly, in glossing Martin's own attempts at signing, I ordinarily base my putative glosses on Terry's interpretations, as in this case. Terry's special role as default interpreter for the signers, or mediator between speakers and signers, deserves a study in its own right-especially the form of her glossing. I merely note her that the job is an ambivalent one for Terry, something she sometimes enjoys but sometimes finds onerous in the extreme. This role, in fact, links Terry and young Vic together, as the only people who bridge the language divide between $\mathrm{Z}$ and Tzotzil, although their age, status, and gender differences (e.g., Terry is an unmarried female, already too old to be of appropriate marriageable age in Zinacantán) also separate their dual trajectories.

5 Morpheme by morpheme glosses for spoken Tzotzil include the following abbreviations A1-A3 (A series or ergative/possessive proclitics in $1^{\text {st }}, 2^{\text {nd }}$, and $3^{\text {rd }}$ person), ANTIP(assive suffix), AP(p)L(icative suffix), ART(icle), (unmarked) ASP(ect), B1-B3 (B series or absolutive proclitic in $1^{\text {st }}, 2^{\text {nd }}$, or $3^{\text {rd }}$ person), CL(itic), EVID(ential particle), EXCL(amation), INC(ompletive aspect), NEG(ative particle), Q(uestion or interrogative sentential proclitic). Dashes $(-)$ indicate morpheme boundaries, and plus signs (+) link combined portmanteau morphemes.
} 
Haviland, $Z$ time, pg. 18

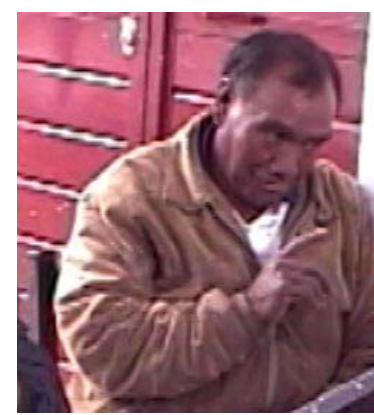

Fig. 30. Martin returning the finger-wave to say 'keep quiet.'

The normal way to denote deaf people in Tzotzil is with the word uma ' which actually means 'dumb,' with almost the same negative polysemy as its English gloss. The salient fact about the deaf siblings in this family was, in fact, that they never learned to speak. It was only when Terry, the third sibling--who also did not speak at all for the first couple of years of her life--suddenly began to spout Tzotzil that the family began to understand the problem was deafness. For the grandparents, the fear that Vic, though clearly able to hear, might also be uma 'was palpable, especially since, from a very early age, Vic clearly was learning to sign, modeling his hand motions and gaze on the signing adults. The ensuing conversation between the hearing family members on this occasion when Vic appears to be imitating the signing of his uncles suggests that this is not entirely a welcome development. Here is how Paula continues.

mu mex-av-ak'-be $y$-il une:

NEG CL ASP-A2-give-APL A3-see CL

"Don't let him see!"

K'u cha'al ta $x$-chan tajmek=e.

What way INC ASP+A3-learn very $=C L$

"He'll just really learn (to sign)."

As Vic continues to attend to the signed interaction between his two uncles, who are trying to figure out what I want them to do with photograph arrays and laptop displays, grandmother is even more explicit about her concerns.

Yik'al mu x-jam-b-on y-u'un y-e yu'van

Perhaps NEG ASP-open-APL-ANTIP A3-cause A3-mouth EVID

"Perhaps no one will be able to open his mouth (i.e., teach him spoken language)." 
Haviland, Z time, pg. 19

li, mi'n ch-0-k'opoj x-a-na'?

EXCL Q INC-B3-talk ASP-A2-know

"Aay, do you think he'll ever learn to speak?"

On the one hand, on this occasion everyone in the family recognized that Vic's signing was a kind of "speech" (or k'op 'word, language'), and that through it he was participating in the interactive social life of the household. The deaf signers-his mother and uncles--were delighted with his baby-signing and encouraged it in quite direct ways, as we shall see. On the other hand, the grandparents and most of the other hearing members of the family were terrified that Vic would not learn to speak Tzotzil, fearful as well of the stigma and misfortune they felt would be his resulting fate. This deep ambivalence was not lost on Vic himself, and it has colored how he construes himself in relation to his linguistic resources as they have grown over the last eight years, the subject of the remainder of this essay.

\subsubsection{Molding}

Vic's signing skills, unsurprisingly, continued to expand during his second year of life, giving him communicative manual skills that far outstripped his early vocalizations, which were mostly limited to a few cries supplemented by conventionalized gestural requests (for being picked up, nursed, etc.). As Vic approached two years of age and signed in ever more complex ways, his caregivers began to manipulate his hands for deliberately communicative purposes. The first such example I was able to record occurred during a picture-matching elicitation task. Jane was about to describe a stimulus photo to the other signers, who in turn were meant to select a matching photo from an array of possibilities. Vic ( 1 y $10 \mathrm{~m})$, seated on Jane's lap, was also looking on a computer screen at the picture which showed several large pieces of firewood piled in their yard (Fig. 31).

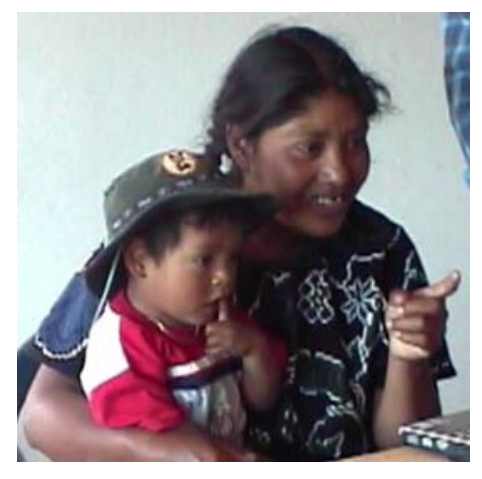

Fig. 31. Vic viewing an image on a computer screen.

The ensuing signed rendition illustrates several notable features of the structure of $Z$. Jane began with a standardized turn-opening sign-a quick downward flip of the fingers of one hand, extended toward her interlocutors (Fig. 32)--which I usually gloss as "HEY!" (Haviland 2015). She then grabbed Vic's hands and ventriloquated a full nominal construction, starting 
with a SASS: here "long in a horizontal dimension" (Fig. 33). There followed a "characterizing" action pattern that suggested how human beings interact with the entity in question: that it was something one carries stacked on one's arm (Fig. 34). (The corresponding highly specific Tzotzil verb is kech 'carry sideways in the arms'.)

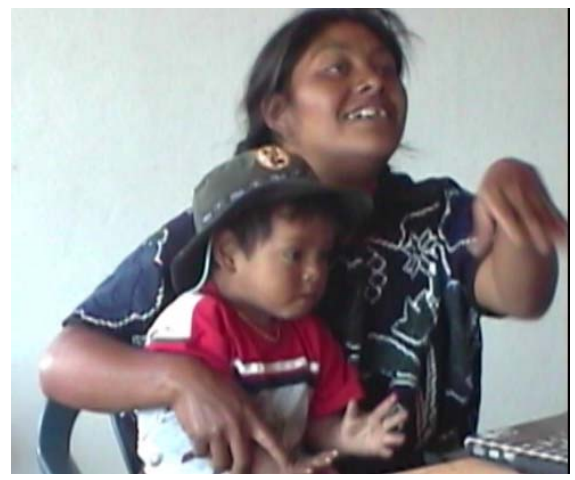

Fig. 32. Jane signing 'HEY' to her interlocutors.

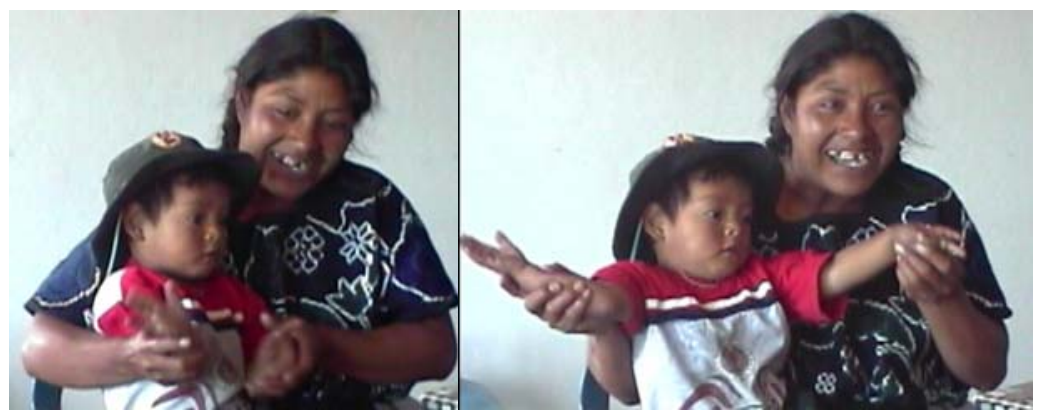

Fig. 33. Ventriloquating the SASS for 'long in a horizontal dimension.'

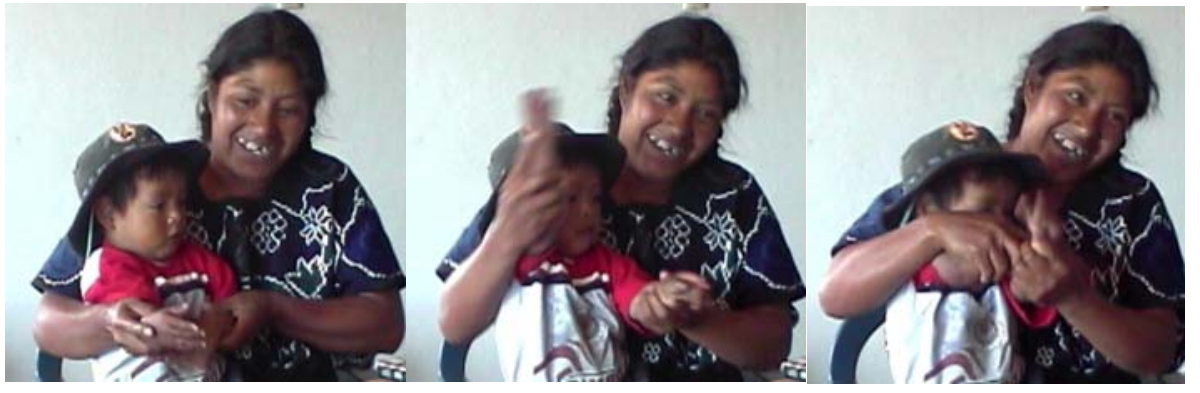

Fig. 34. Characterizing the entity in question as something carried stacked on one's arm.

Jane illustrated what in the sign-language literature is called "molding," often observed between deaf parents and their young children. As Julia Maestas y Moores (1980) put it: "Molding, or physical guidance, is the common practice of holding the infant's hand or hands and moving it or them in the action of the sign intended." Note that because she manipulated Vic's wrists rather than his hands, Jane had limited control over the handshapes he adopted and instead could only emphasize the well-defined trajectories of his limbs. Nonetheless, she 
did manage to configure Vic's left arm in an evocative way, to convey the desired image, in a repetition the characterizer sign (Fig. 35).

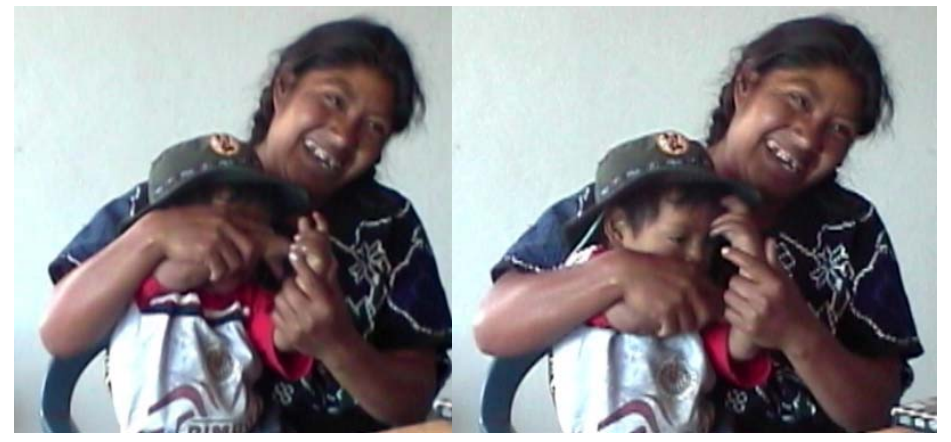

Fig. 35. Using Vic's arm to repeat the characterizer.

Jane's interlocutors laughed, and they had no trouble immediately picking the correct matching photograph.

Vic quickly managed to extricate his hands from Jane's grasp. However, if one imagines molding to be at least partly a teaching device - to help Vic learn to sign-what he did next indicated that Jane had succeeded. Vic seemed to try to reproduce at least part of what Jane had just signed. He started with an (uninterpretable) sign in the syntactic slot for the SASS (Fig. 36). Then he copied Jane's 'carry' sign, although with a defective "baby talk phonology" (since he did not have his left arm correctly configured) ${ }^{6}$ and then repeated it in reduced form (Fig. 37).

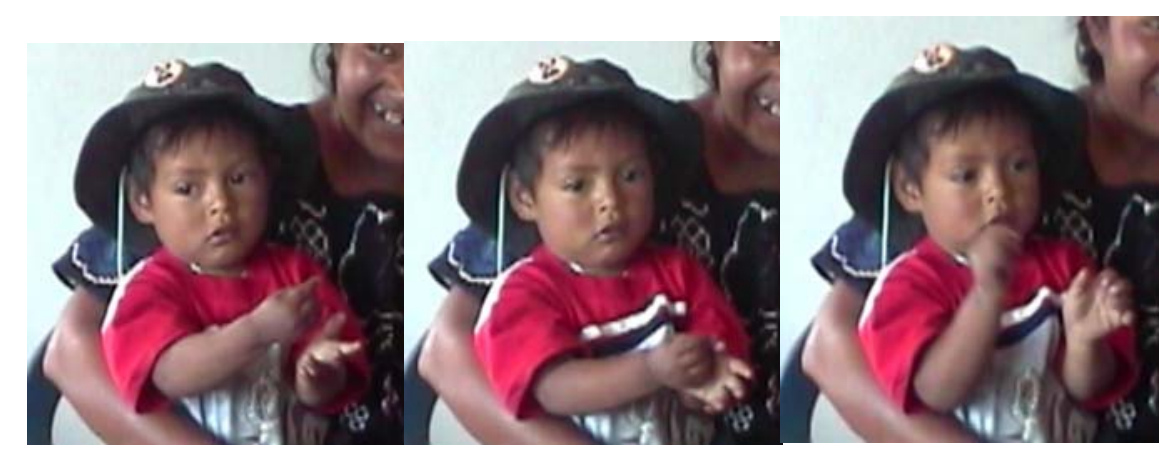

Fig. 36. Vic making an uninterpretable sign for the SASS.

\footnotetext{
${ }^{6}$ His childish "pronunciation" was sufficient to confuse a hearing signer-in this case, Rita, not Terry--when she watched the film out of context. She thought Vic was trying to say something about a wristwatch or the time of day.
} 


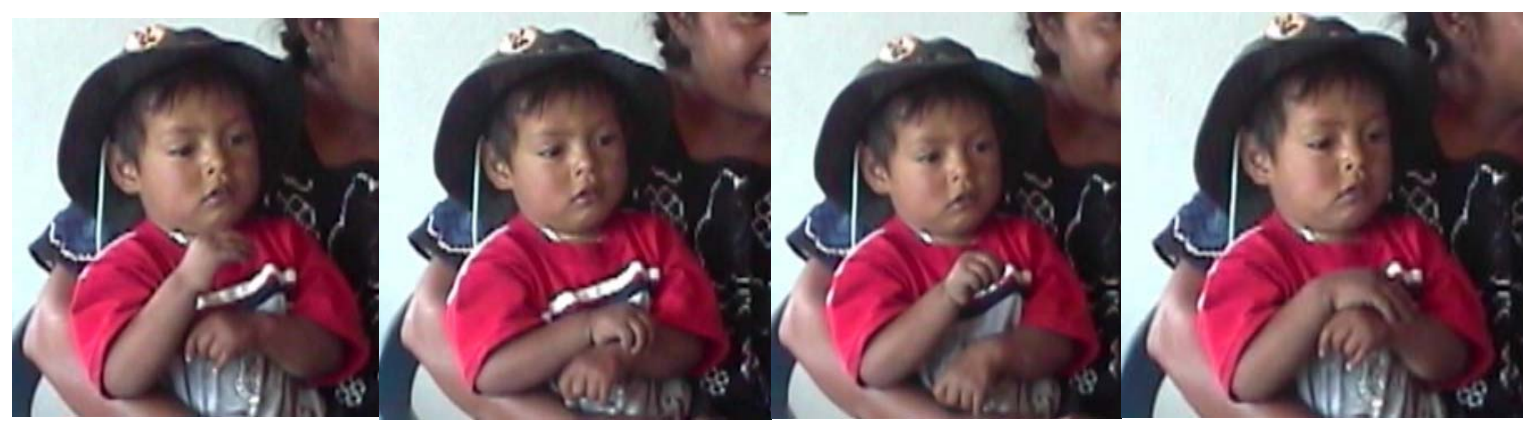

Fig. 37. Vic signing a reduced, baby-talk version of Jane's 'carry' sign.

Such explicit and physically direct language teaching gives us a further glimpse of what language learning means, both to mother and child. Jane appears to have felt free to use Vic's hands to sign her own message-direct evidence about (1) the central features of sign form she considered important enough to mold (thus, her ideas about $Z$ linguistic structure), (2) her presumed rights over his body and behavior as mother (thus, her conception of what sort of person he was at this age), and (3) as language teacher, her interests in his developing notions of "proper" sign structure (thus, her ideologies of Z as language: what it does, what it's good for, whose it is). By the same token, Vic both allowed himself to be partially molded but also resisted Jane's manipulation, trying by the end of her ventriloquation to free his hands and sign by himself. He thus seemed to understand that his mother was showing him a correct way to do something and encouraging him so to act. That he went on to try to reproduce Jane's proxy signing also suggests that even at this very young age, he had a notion of formal and communicative targets to which to aspire, and a sufficient sense of self and (interlocutory) other to inspire him to sign autonomously.

\subsubsection{Banishment}

Shortly after his second birthday, a major change occurred in Vic's life. Vic's grandmother Paula - the undisputed head of the household--decided to send the child from their home in the village to live instead with her older daughter, Josie, who ran a small vegetable stand in the nearby Mexican town of San Cristóbal. Josie, the divorced mother of the fluent signer Rita, had spent much of her life on her own since Rita was born, making a meagre living from weaving and selling to support herself and her daughter, who was left to grow up in the grandparents' household as Josie herself scrambled around in search of income, sometimes spending as long as a year away in tourist centers like Cancún. At this point, Josie's little shop in town was a frequent stop for all of the members of the extended $Z$ household when they visited San Cristóbal. One of the main reasons given for moving Vic there was for him to give up signing, learn proper Tzotzil, and perhaps some Spanish as well (although in fact almost all of Josie's customers were Tzotzil speaking exiles from Indian villages in the region). To help him break his close relationship with Jane, he was encouraged to call Josie me 'mother,' and she even began to offer him her (empty) breast as comfort. 
Vic's stay in San Cristóbal, with reduced contact with his biological mother, lasted about 10 months, during which time his progress in spoken Tzotzil was, not surprisingly, rapid and profound. He spent most of his time with his aunts Josie and Terry, who encouraged him to communicate only by speech. On his infrequent visits to the village, however, Jane was still his primary caregiver, although in various ways his interactions with her changed, partly reflecting explicit indoctrination by those in the family who considered Jane essentially incapable of caring for him properly. (As a practical matter, with no easy sources of income, Jane had no money to devote to Vic's needs, which were largely met by Josie and Terry's earnings at the store, supplemented by the occasional salaries his uncles earned as masons.)

One particularly telling example of Vic's changing linguistic repertoire (not to mention his changing relationships with his caregivers) during this period is the following extract from an interaction when, 3 months after he had moved to town, Vic visited the village briefly on a weekend. Almost all of the women in the household were preparing to walk across the village to a Sunday market, and Vic was eager to accompany them, although his mother Jane had not herself planned to go. When he began to complain about being left behind, Jane was instructed to dress him in a new shirt and take him along.

I was filming Vic and his mother as preparations were underway for the group to set out from the house, and Vic was alternately interacting with me (with whom he usually used signs at the time, although he knew I also spoke Tzotzil), his mother (who he knew could not hear), and a couple of the hearing signers, especially Terry who had brought him to the village earlier that day. He feigned sleep for my benefit, hid his face from the camera (as many Zinacantec children are taught to do--Fig. 38), and showed off his new shirt, which prompted his mother to rearrange it by rolling up his sleeves - a process with which Vic cooperated, offering up first one arm and then, following his mother's explicit (touched) request, the other (Fig. 39), all of this without spoken words.

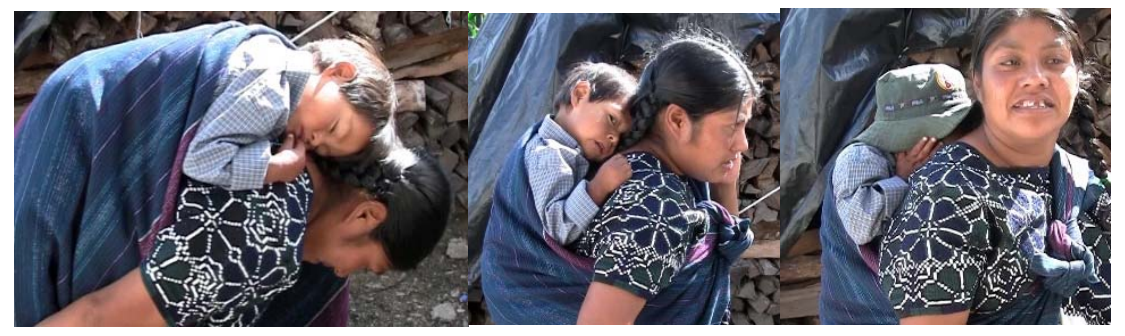

Fig. 38. Vic exhibiting appropriate behavior for children in front of cameras. 
Haviland, $Z$ time, pg. 24

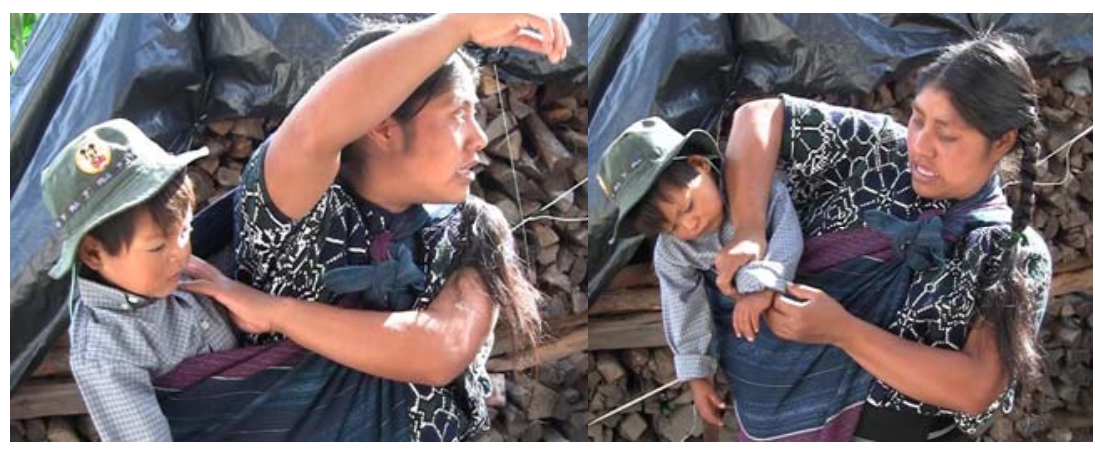

Fig. 39. Mother and son cooperating to rearrange Vic's shirt.

His mother tried to wipe his face (Fig. 40), meeting resistance (as he pushed away her hands with a cry), and also scolded him (with a frowning face and small vocalizations) for fiddling with his buttons and cuffs (Fig. 41). Still he did not speak, except that in response to one of Jane's frowns he said tak'in 'money' (Fig. 42) and threw out his arms wide (in a gesture Terry, who was then was of his principal surrogate caregivers, later interpreted as meaning "all our money was spent [on this new shirt]").

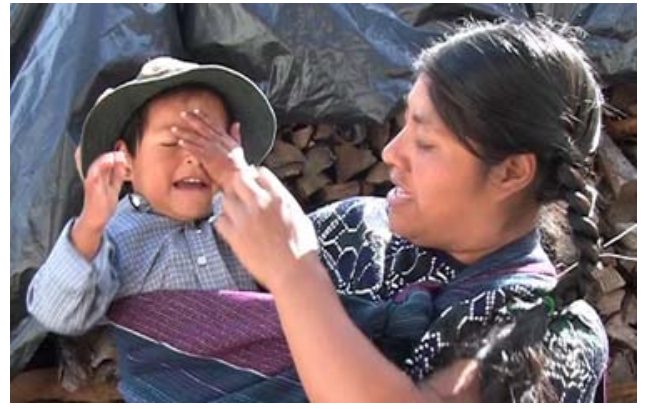

Fig. 40. Jane attempting to wipe Vic's face.

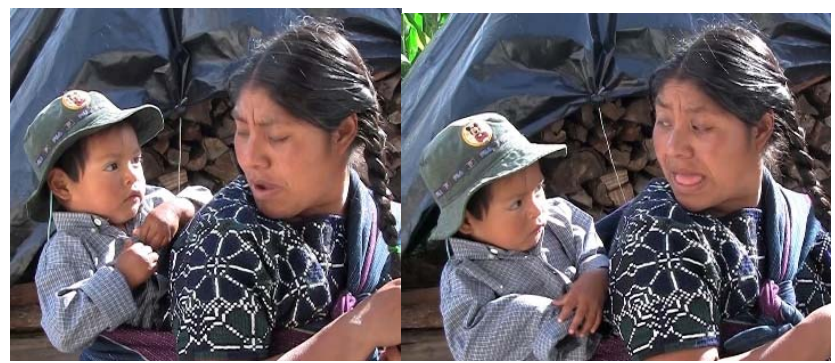

Fig. 41. Jane scolding her son for fiddling with his shirt. 
Haviland, $Z$ time, pg. 25

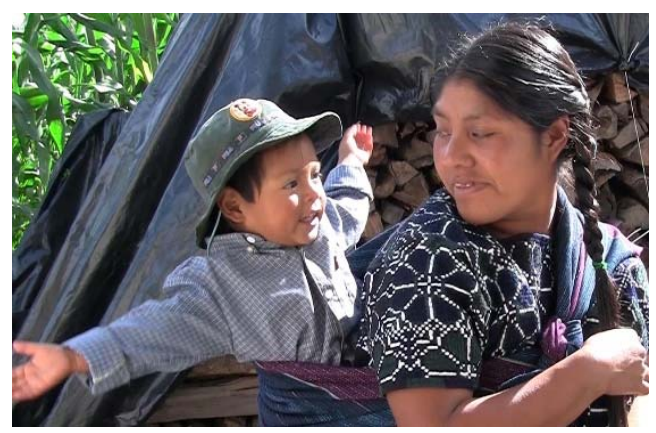

Fig. 42. Vic signing for 'all our money was spent (on this new shirt).'

Shortly afterward came the sequence of most interest for present purposes. It gives evidence both of Vic's careful partitioning of his social world into those who used Tzotzil and those who used $Z$, and of his changing relationship with his mother in particular. As he waited just outside the door of the house, tied to his mother's back, he became increasingly agitated as the other women prepared to depart the house. One by one as they passed he addressed all of them saying in Tzotzil batik "Let's go!" in a whining voice (Fig. 43), once repeating the same plaintive request to no one in particular in such a way that his mother perceived that he was talking but clearly could not understand him (Fig. 44).

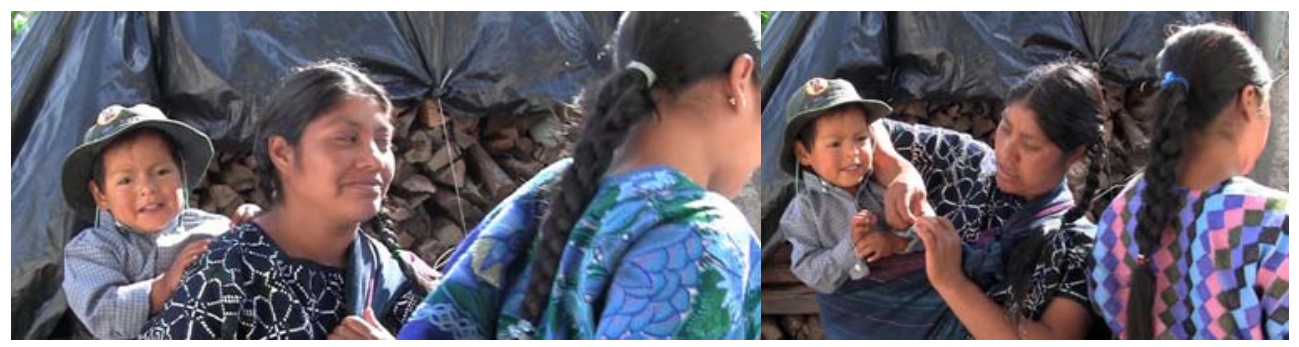

Fig. 43. Vic addressing passersby with a spoken "Let's go!"

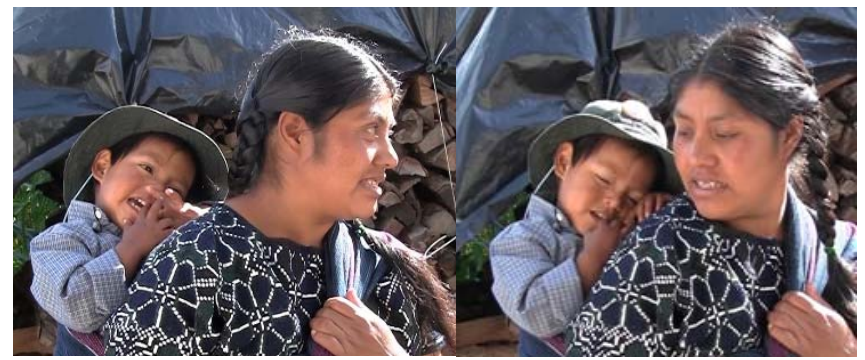

Fig. 44. Jane perceiving Vic is speaking.

Finally, seeing that his mother showed no signs of joining the other women, he resisted any further adjustments to his new shirt (Fig. 45), and launched a highly demonstrative code-switch to $Z$ signing. 


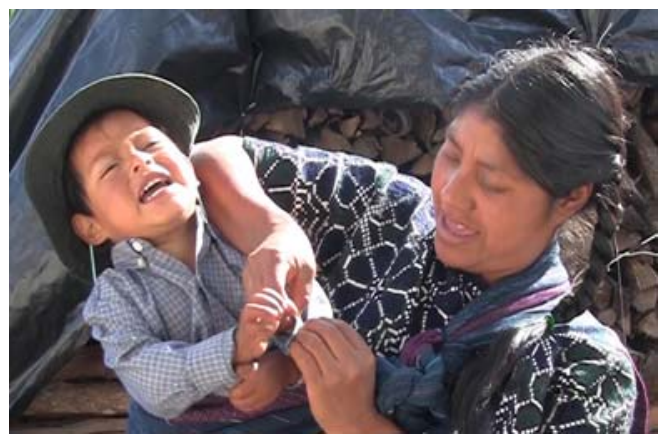

Fig. 45. Vic resisting adjustments to his shirt.

Pushing away his mother's hands, he pounded hard four times on her shoulder to get her attention (Fig. 46). (She was at that moment trying to converse in $\mathrm{Z}$ with me, behind the camera.)
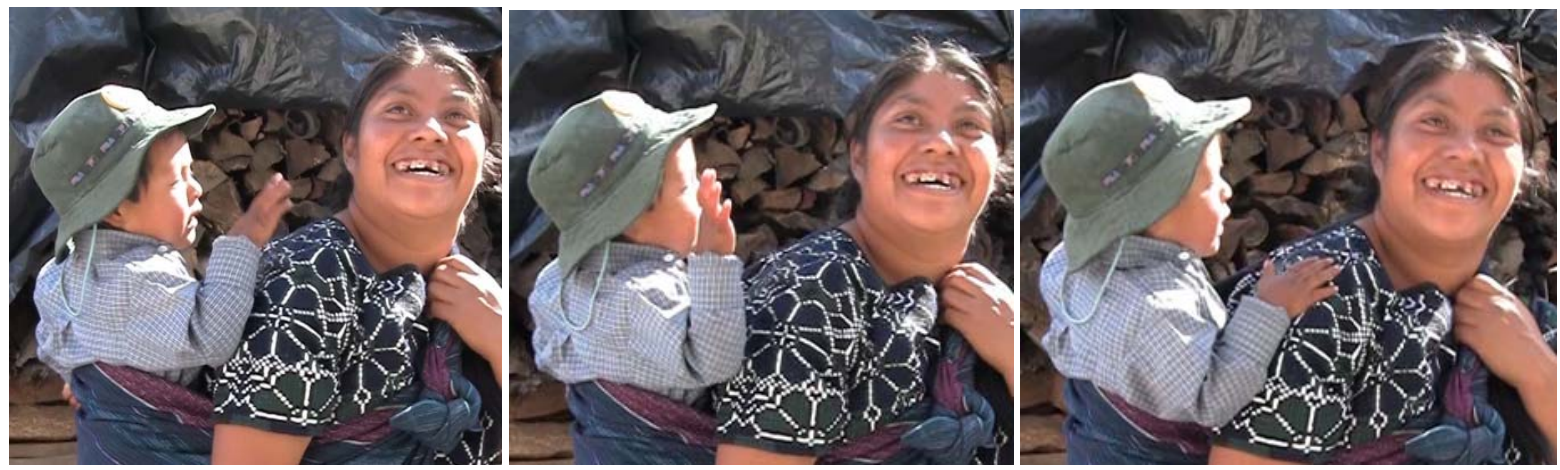

Fig. 46. Vic attempting to get his mother's attention.

Responding to his obvious impatience, Jane started to move away from the door, but Vic was not satisfied. He took hold of her ear and, in perhaps the most direct form of the $\mathrm{Z}$ "HEY" sign imaginable, physically yanked her head around to face him (Fig. 47). Having her full attention at last, without a sound he repeated "Let's go" in fluent Z signing (Fig. 48), and off they went to join the others.
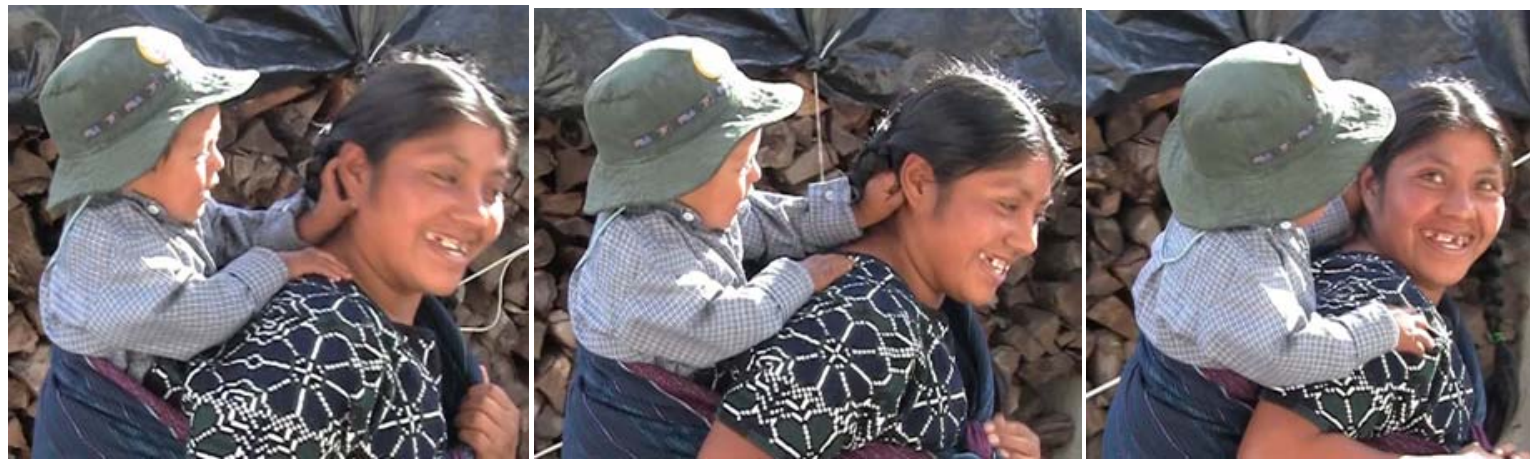

Fig. 47. Vic vehemently grabbing Jane's ear to sign 'HEY.' 


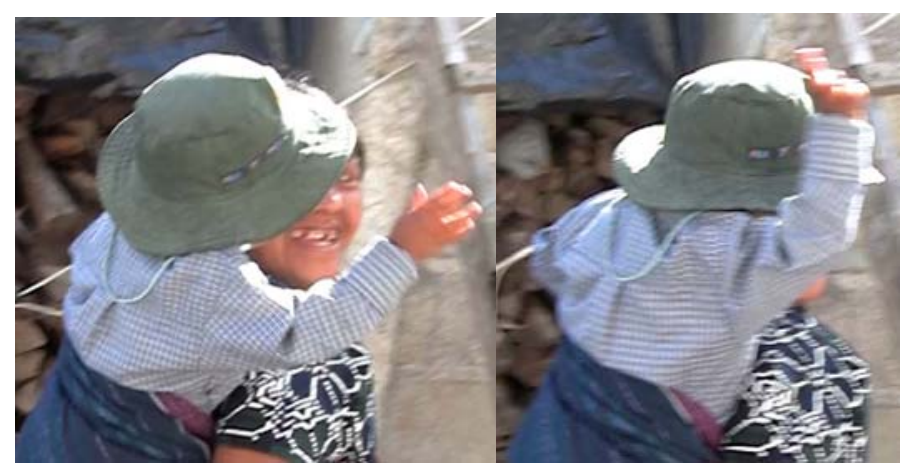

Fig. 48. Vic fluently signing 'Let's go' to Jane.

An obviously central aspect of growing up as a bilingual signing and speaking child is learning to partition the world into those who sign and those who speak (and learning to manage the overlap both in interlocutors' competencies and complex circumstances). The resulting communicative choices identify the child now with one group of interlocutors and now with another. The asymmetries of power and authority between mother and childalways a point of growing contention with two-year-olds-were exacerbated for Vic by the indoctrination he constantly, if indirectly, received in San Cristóbal from his hearing aunties, that his mother-whom he was taught to call, in Tzotzil, not me 'mother' but me 'el 'old lady'7 - was not a fully competent person, a bit chich 'foolish'. He was thus learning, by way of his complex communicative repertoire, to locate himself in a world of power and authority that dismissed signers - and most particularly his mother-as partial, dependent, and deficient, by contrast with hearing people.

\subsubsection{Return to the signing household}

Just around the time Vic turned 3 years old, circumstances changed again, and he returned to live more or less full time with the extended family, having in the meantime become an accomplished verbal interactant. (Resuming life in the village, he also came to the attention of the local school teacher, who pulled strings to have him admitted to a pre-school class at an unusually young age precisely because she learned that his mother was deaf.) Thus, although he spent long periods out of the house, at school, he once again came into close contact with both his mother and his deaf uncles, so that his socialization into both spoken Tzotzil and $Z$ continued intensively.

Vic also began to participate more directly in the eliciting sessions that the signers endured as part of my research project. The implicit metalinguistic instruction that Jane's molding had provided more than a year earlier now began to take a more explicit form. Here,

\footnotetext{
${ }^{7}$ This is how his aunties themselves refer to her, sometimes applying the same epithet chich to the two deaf uncles. Vic similarly was taught to call his deaf uncles mol 'old man' for Frank and k'ox 'small' or 'boy' for Will, triangulating the aunts' perspective rather than his own. (Vic sometimes spontaneously calls Frank jtot 'my father'; his relationship with Will is more fraught, as the latter tends to tease and mistreat him somewhat mercilessly.)
} 
for example, Vic at 3y $5 \mathrm{~m}$ was sitting with his uncle Will, who was about to describe a short video clip of a boy shoving a dog. Will decided to make Vic sign the scene, but he tried to "mold" certain grammatical refinements, not seen in the previous molding example, including the specific phonology of handshapes, complicated syntax, and a developed lexicon. He took the boy's hands in his own, carefully sculpted them into the conventional handshape for the $Z$ sign for 'dog,' and demonstrated the appropriate motion for the fingers, until Vic performed the sign to Will's satisfaction (Fig. 49).
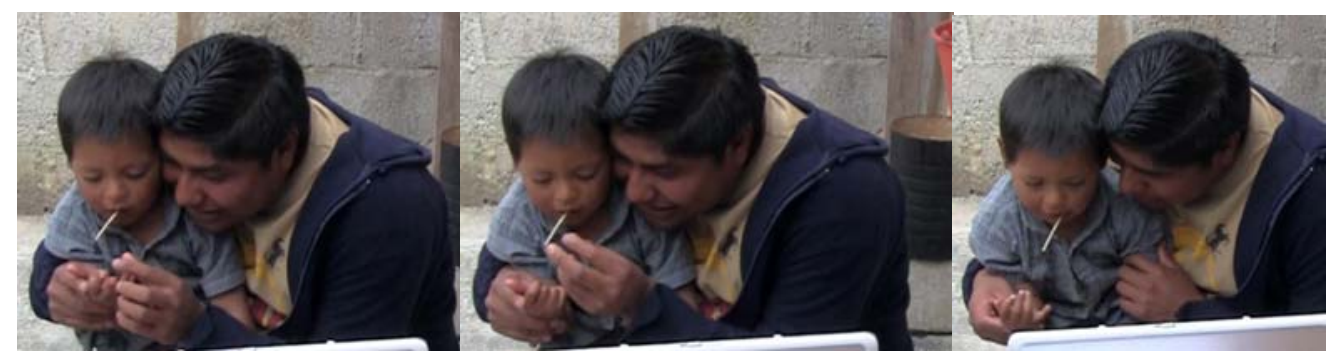

Fig. 49. Will carefully teaching Vic the $Z$ sign for 'dog.'

Will then moved Vic's arms and hands to sign the pushing motion (Fig. 50).

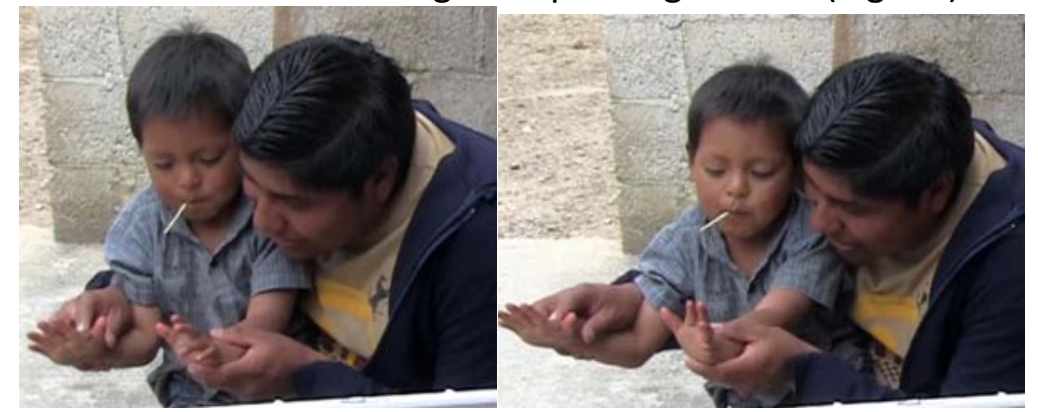

Fig. 50. Will helping Vic to sign the proper motions.

For the next example-a scene in which a boy lifts a bicycle-Will also induced Vic to sign a nominal 'bicycle' by means of a bare SASS (Fig. 51), followed by a verb (Fig. 52), an example of an apparent minimal default clausal syntax for such actions, consisting of just Object (itself a minimal SASS) plus Verb.
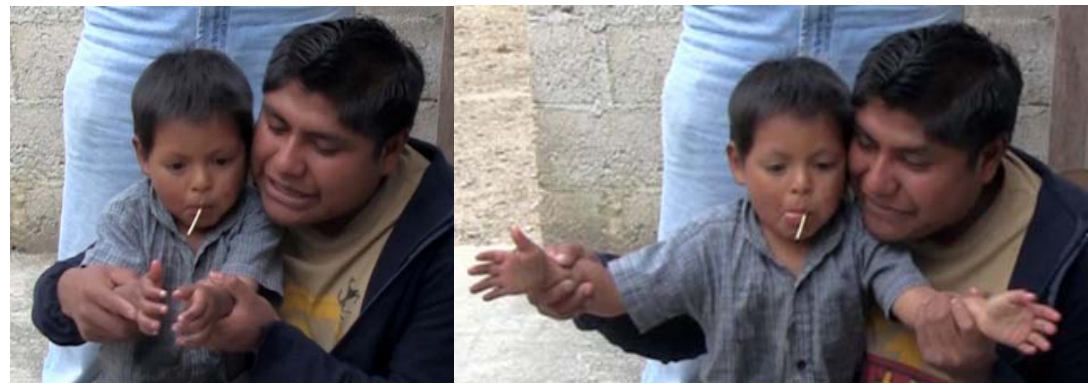

Fig. 51. Will and Vic signing the SASS for 'bicycle.' 


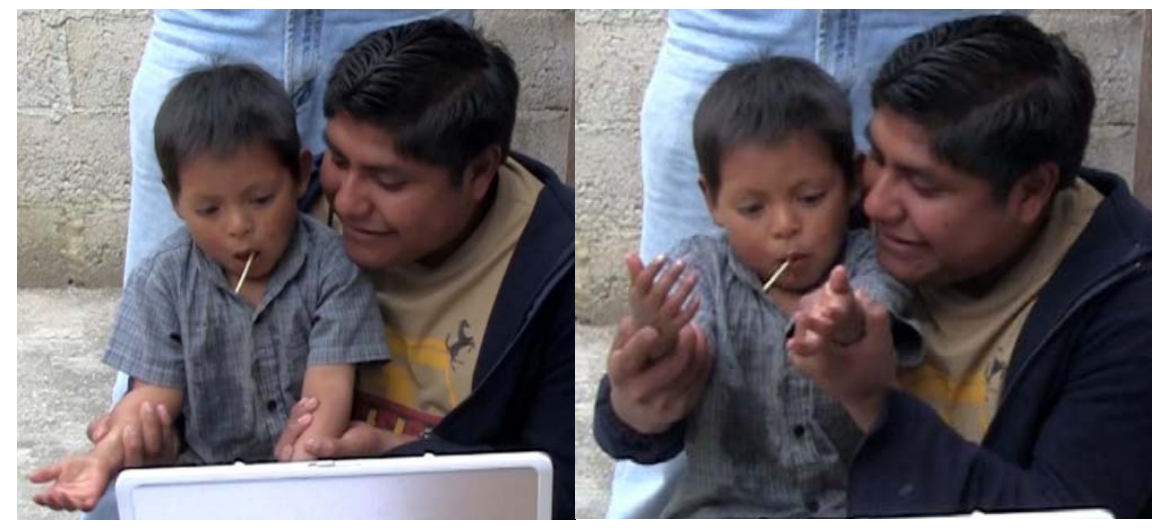

Fig. 52. Signing the verb accompanying the SASS.

Because his interlocutors were unable to identify the matching scene from Vic's molded signing, Will went on to clarify what he meant. With his own hands, he repeated the SASS (Fig. 53), added a characterizing action (Fig. 54) to it to form the nominal 'bicycle,' and then repeated the verb 'lift' (Fig. 55). (Recall Jane's default 'chicken' in Fig. 4 versus Will's syntactically and semantically elaborated version in Fig. 2 and Fig. 3 above.)

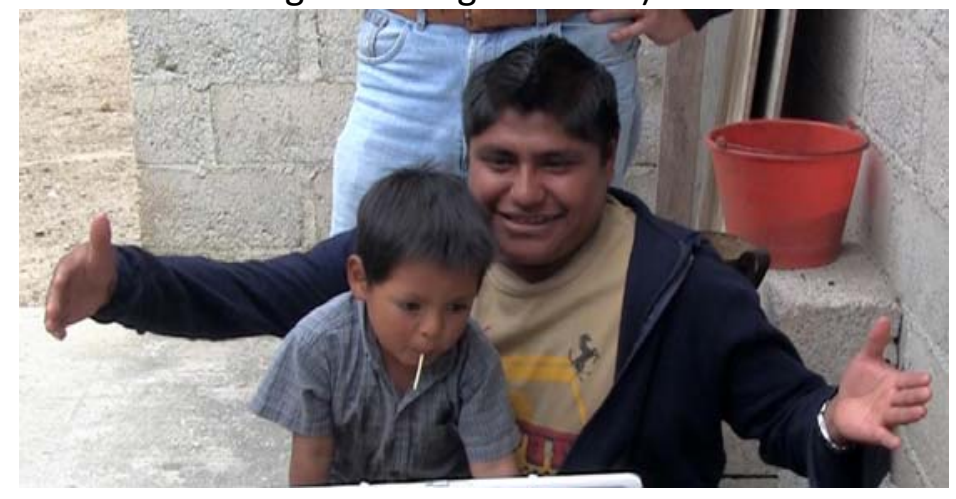

Fig. 53. Will repeats the SASS using his own hands.

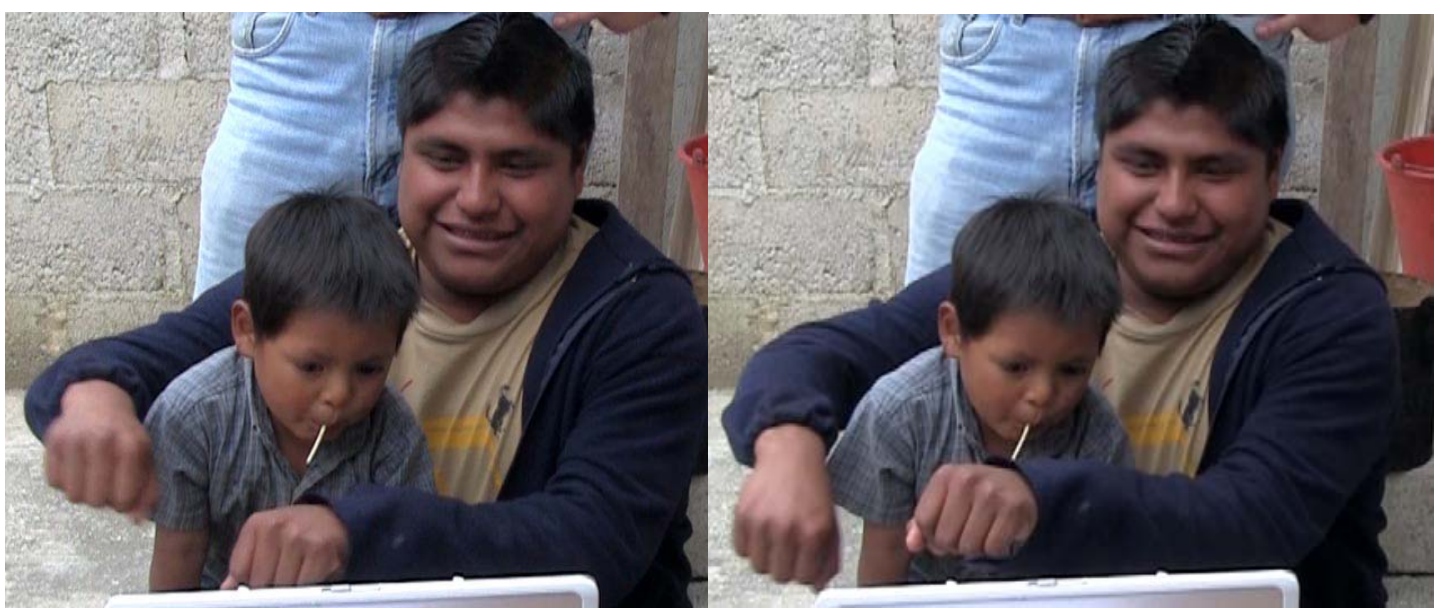

Fig. 54. Adding a characterizing action to indicate 'bicycle' more clearly. 


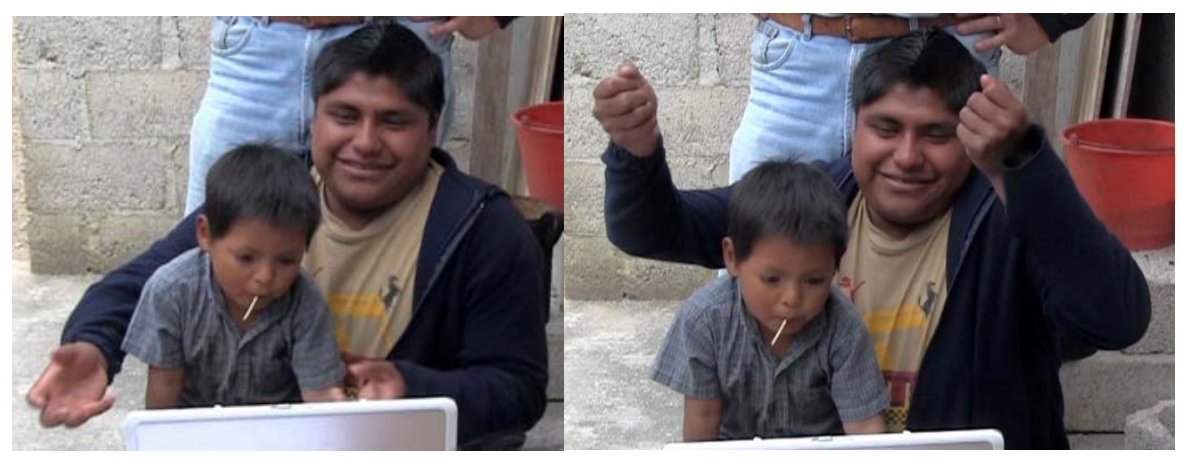

Fig. 55. Repeating the verb 'lift.'

Vic had again allowed himself to be "molded," and he paid close attention to the details of the resulting signing, especially the carefully sculpted handshapes-a rough analogue of correcting a child's "baby" pronunciation in speech. He thereby seemed to have accepted a kind of projected self-definition as a child not yet quite able to sign properly. However, at this age he had limited patience with the game, resisting Will's handshape molding with the next stimulus video (Fig. 56).
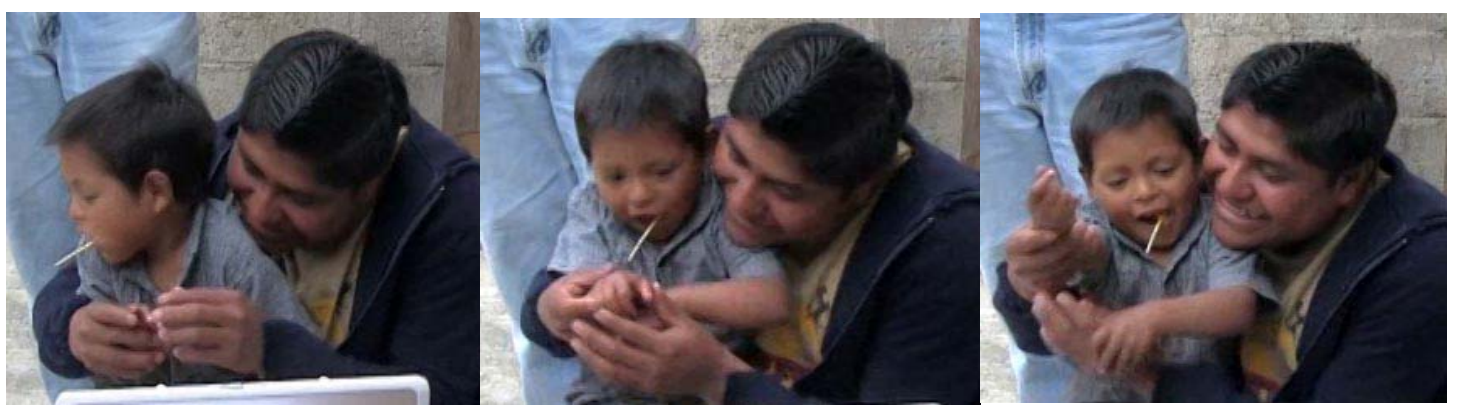

Fig. 56. Vic resisting Will's handshape molding efforts. 
Still, as he had done 18 months earlier with Jane, Vic seemed immediately afterward to want to demonstrate that he had learned from Will's little lesson. He started to sign the next scene spontaneously, still sitting in Will's lap. The video was an early clip of Victor himself, driving his toy tractor into a spinning toy top. He signed TOP with an action pattern showing how the toy is spun (Fig. 57), followed by TRACTOR (Fig. 58), with a driving action, and then he signed the number ONE, perhaps because he alone was driving the tractor on the video (Fig. 59). Will immediately corrected Vic's ONE to THREE, since both Will and Jane were also present in the scene (Fig. 60 ).

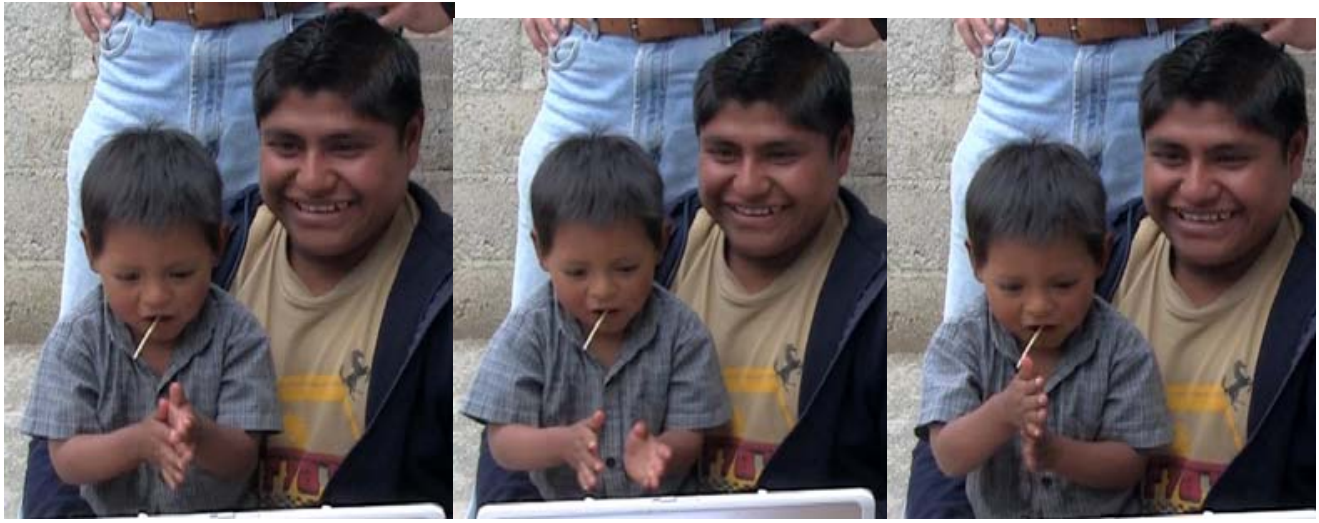

Fig. 57. Vic using an action pattern to sign 'top.'

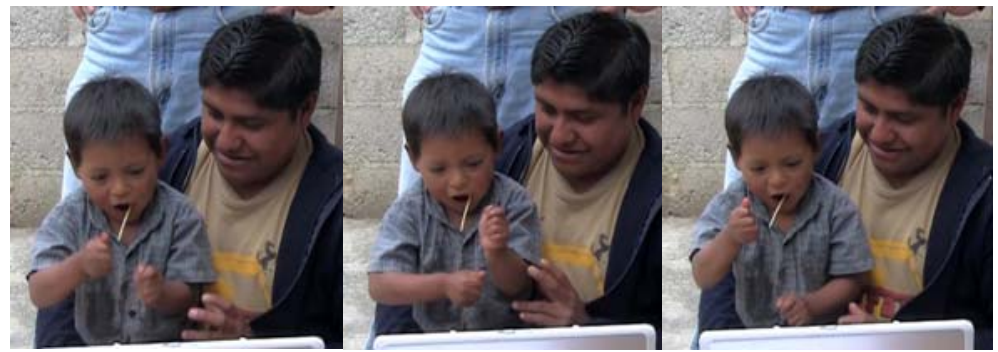

Fig. 58. Signing 'tractor' with a driving action.

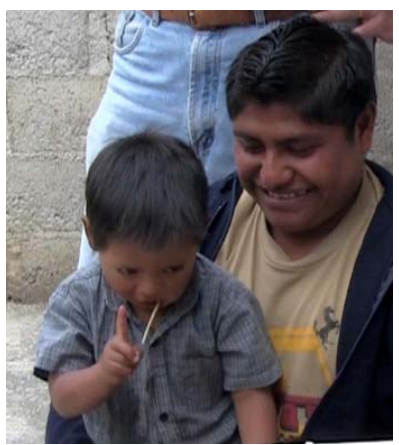

Fig. 59. Vic signing 'one' because he alone drove the tractor. 


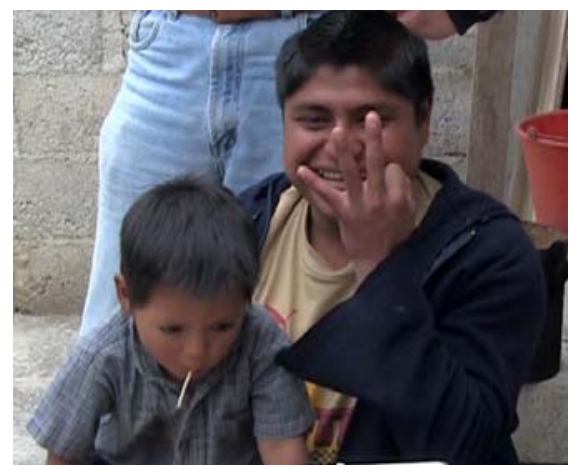

Fig. 60. Will correcting Vic by signing there were 'three' people.

Vic's seemed to accept his uncle's good-natured molding as neither unexpected nor inappropriate for a child still learning from adults, but he also demonstrated both confidence and competence in the descriptive task. He clearly seemed to believe that he knew perfectly well how to sign what he had seen in the video, and by volunteering to participate in the elicitation he displayed his growing confidence in signing.

\section{The differential affect of normativity}

By the age of four Vic had mastered the delicate synchrony of gaze, pointing, and signing to be able to participate in quite sophisticated interaction with the adult signers. His signing, however, still had elements that reflected his unique upbringing and socialization into language. For example, Vic had learned the "neck jerk" action pattern that is part of the fullblown Z sign for 'chicken' we met above (Fig. 2 \& Fig. 3) by the time he was just 2y 3m of age. (Although I wasn't able to catch it on film, he once spontaneously made the sign for me when he showed me the empty chicken yard behind Josie's store in San Cristóbal.) Nonetheless, Vic also frequently produced only Jane's simplified SASS form to sign 'chicken,' as one might expect from a child whose first and principal $Z$ teacher had been his mother. As I describe elsewhere (Haviland 2013) when he was four and a half, Vic described a picture containing a chicken in just this way to his uncles, who corrected him indulgently, leaving the impression that they were delighted by any evidence that he could sign competently and willingly, and clearly encouraging him to follow the standards they themselves had set. Vic performed a somewhat abashed version of the neck jerk after this correction, laughing at himself as he did so (Fig. 61).

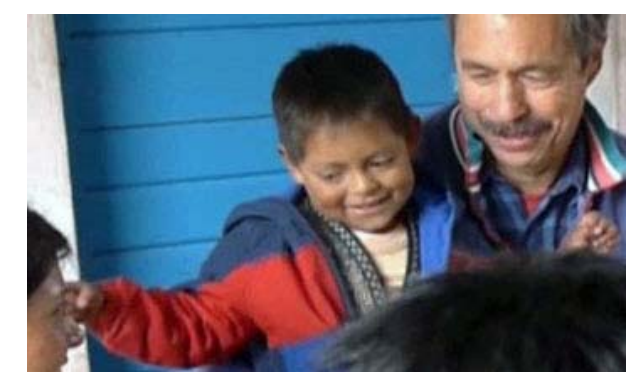

Fig. 61. Vic laughing at himself as he signs the neck jerk for 'chicken.' 
As a child of 8, Vic often avoided the formal eliciting tasks I still inflicted on the adult signers, preferring instead to play with his Android tablet (a much envied gift from California) or to make mischief around the yard. Sometimes, however, boredom led him to join the other signers. The sorts of adjustment adults made to his signing reflected his changing relationship with the other members of his miniature sign community, even though his life increasingly began to take him away from it. The kinds of meta-linguistic interactions in which he participated also demonstrated how different was his position in this tiny social system from that of his mother Jane, the final topic I will address here.

The last time I saw adult signers "mold" Vic's signing hands was just before his $7^{\text {th }}$ birthday. By then Vic did not lightly suffer having his hands manipulated by anyone. Nonetheless, on this occasion his uncle Will used a version of molding to paint sentences partly with and partly on Vic's body, to emphasize quite specific grammatical points about Z clausal syntax: the classic question of "argument structure" or who does what to whom. Vic had been retelling a Charlie Chaplin film in which Chaplin, equipped with the ricketiest of barber chairs, tries to shave a customer. The customer has been reading a newspaper, and Chaplin lathers him up. Vic rendered the scene by modeling a person with head thrown back, and he used his hands to demonstrate lather being applied to his chin and neck (Fig. 62). ${ }^{8}$

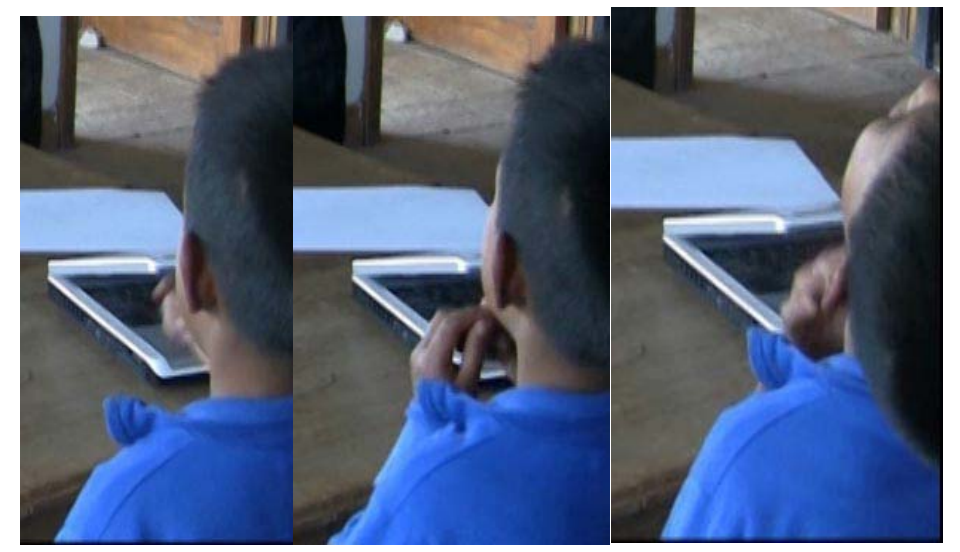

Fig. 62. Vic reenacting a scene from a Charlie Chaplin film.

Will, on whose lap Vic was sitting, immediately intervened. He reformulated Vic's utterance to show, I believe, that the man getting lathered was the logical patient, and that the one applying the lather was a separate agent. First Will took hold of both of Victor's hands and spread them wide to illustrate the customer holding up his newspaper (Fig. 63). He then used one of his own hands to throw Vic's head back and moved Vic's hands up to his neck with appropriate motions to suggest the customer-still holding his newspaper--being lathered up by the barber (Fig. 64). That is, he both molded Vic's signing, and simultaneously used Vic-

\footnotetext{
${ }^{8}$ Unfortunately, because of technical problems on that day, I can offer only a back view taken by a B camera meant to film the audience rather than the signer, so the reader will have to conjure the scene with the help of some imagination.
} 
appropriately arranged-as a prop for his own signing, in order to clarify a potential confusion over argument structure and the agent-patient relationships in young Vic's original signed rendition of the scene. Vic seemed not to object to his uncle's intervention, and, indeed, he both accepted the correction and laughed along with the rest of us about its comical form.

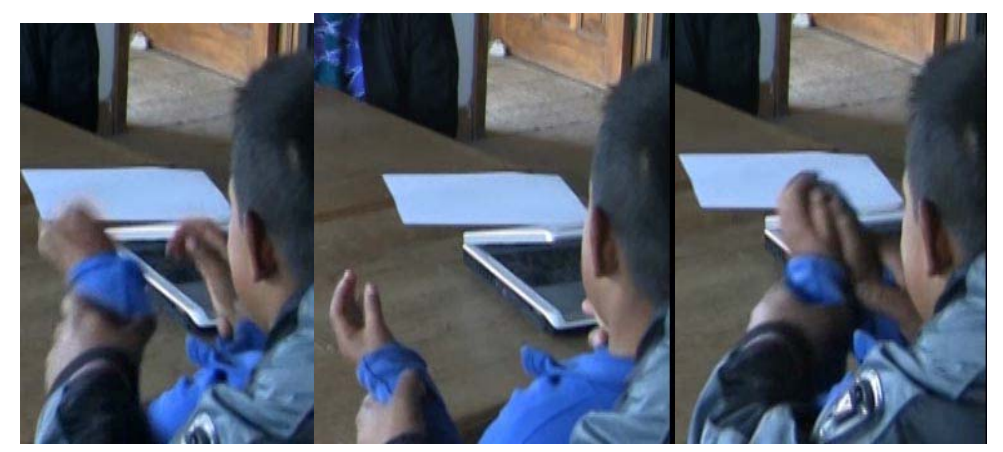

Fig. 63. Will (out of view) modeling Vic's hands to illustrate a customer holding a newspaper.

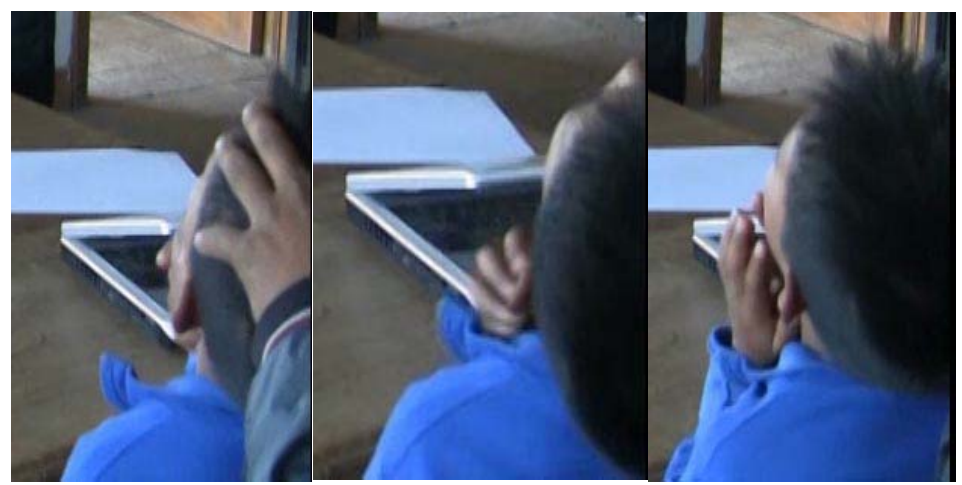

Fig. 64. Will pulling Vic's head back to depict the customer getting lathered up.

The limited literature on molding in developed sign languages concerns itself with differences in interactive styles among parents of deaf children, especially those who sign and those who do not (Maestas y Moores 1980, Orlansky \& Bonvillian 1985, Pettito 1990, Folven \& Bonvillian 1991), or, even more commonly, with methods for teaching (limited) sign language to individuals (from apes to autistic children) deemed to have language-learning deficits of one sort or another (Fouts 1972, Bonvillian \& Nelson 1976, Fulweiler \& Fouts 1976, Carr et al 1978). In Z, on the other hand, I take molding as evidence for a schematic but quite explicit notion of well-formedness - a hallmark of language--that adult signers evince in optimistically teaching the few potential second-generation learners. For young Vic, having his hands manipulated into sign was clearly one way of encouraging him and welcoming him into the community of signers, even in the face of considerable ambivalence in the wider family about his signing at all. It was also a forceful reminder to him about what Bauman (1984) might call his maturing "responsibility" as a performer of sign: since it is meant for others, signs must serve the purposes of the conjoint actions at hand, in this case by being clear and relatively unambiguous about the scene being recounted in order to facilitate the interlocutors' comprehension.

\subsection{Innovation in sign form}


My last examples are drawn from video recordings of Vic's explicit socialization into Z signing, when he was just turning 8 . By this point he was already a highly competent signer and speaker, attended elementary school, and was on the cusp of the age when many Zinacantec boys start doing paid labor outside the home. He had also become a kind of default interpreter for his mother and uncles, often replacing Terry and Rita in this role because of his allegedly more reliable ability to pass messages back and forth across the language divide. The examples are drawn from spontaneous discussions in the interstices of formal eliciting. I offer them to motivate conclusions about how the time scales of an emerging language and those of the lives of its users merge and diverge, and can be re-laminated one on top of another, propelling individuals who participate variously in the scale of languages we have seen into different personal trajectories.

Consider Vic's way of signing 'cat' (Fig. 65), identical in most circumstances to the polysemous sign which also means 'dog' shown earlier (Fig. 49). At the time the video was recorded, Vic had over a period of several months been recounting scenes from animated cartoons in which a cat was a prominent character. His signing had been routinely accepted (and understood) without comment during all this time.

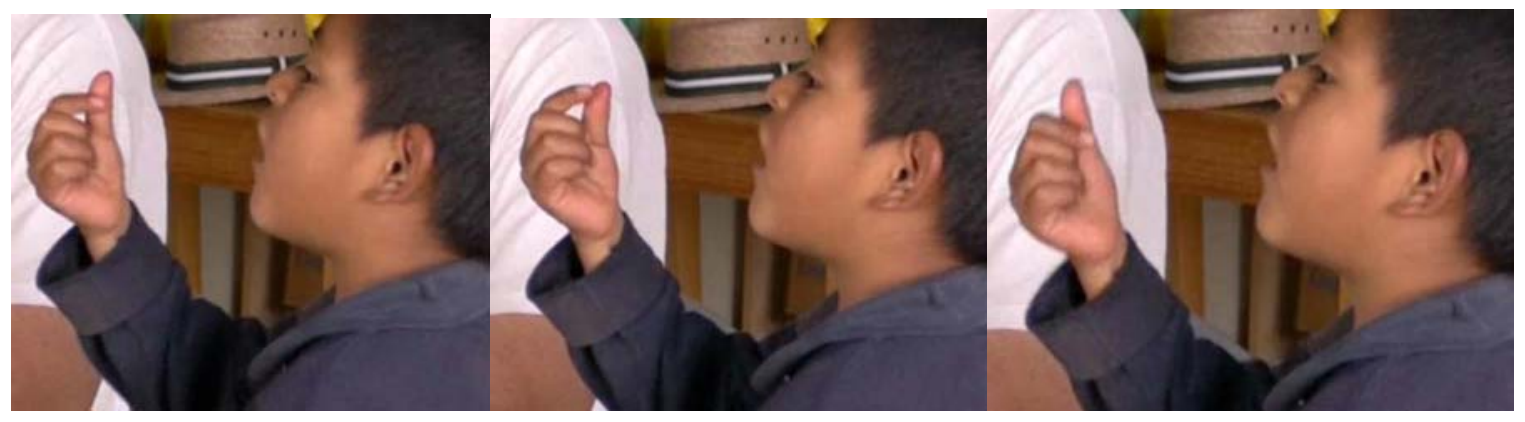

Fig. 65. Vic signing his version of 'cat.'

However, on this occasion, for some reason his performance prompted a string of metaphonological reflections, starting with one from Will just after he had correctly picked the correct stimulus picture. Will can be seen to look at is own hand as he imitated Vic's sign (Fig. 66) and then call Frank's attention to its form, which involved rubbing the first joint of the index finger across the thumb. Will followed this demonstration with an interrogative handshape (Fig. 67) directed at Frank. 
Haviland, $Z$ time, pg. 36

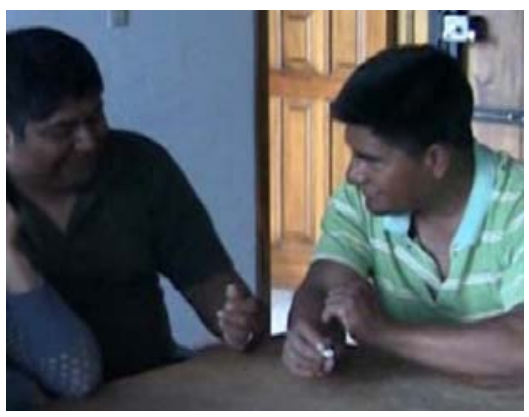

Fig. 66. Will imitating Vic's signage for 'cat.'
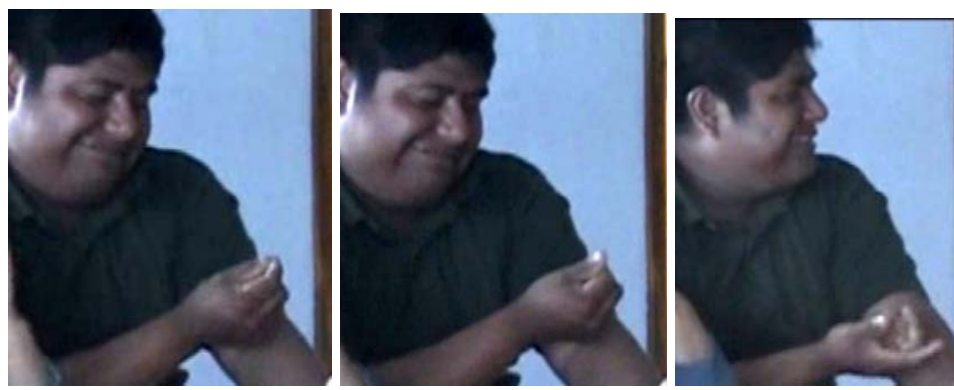

Fig. 67. Will calling Frank's attention to the signing with gaze and an interrogative handshape.

Will continued with a signed pun, pointing out that, for many Zinacantec Tzotzil speakers (although not in Z sign) the same handshape is a gestural emblem meaning 'money' (Fig. 68). Frank laughingly agreed, using two different $Z$ signs for money: the fingers and palms of both hands passing over one another, for 'banknote,' and a thumb and forefinger grip handshape, for 'coin' (Fig. 69).

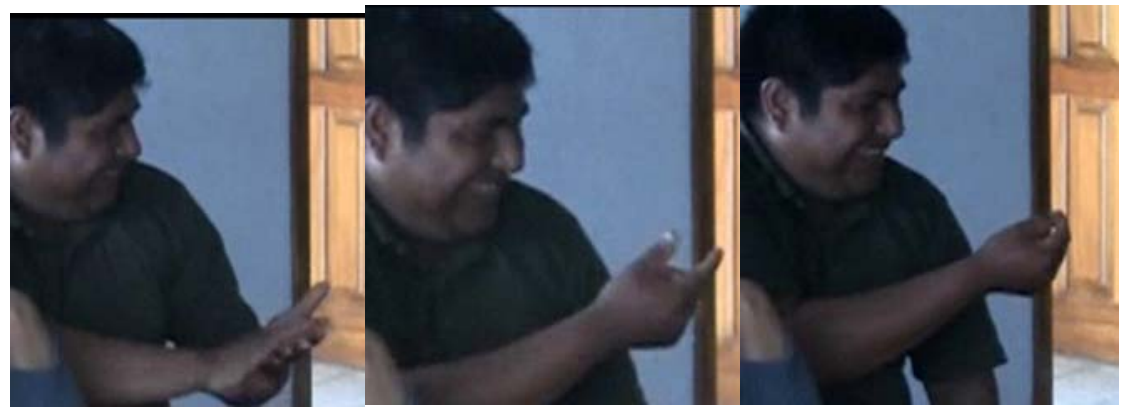

Fig. 68. Will signing a pun for 'money.' 


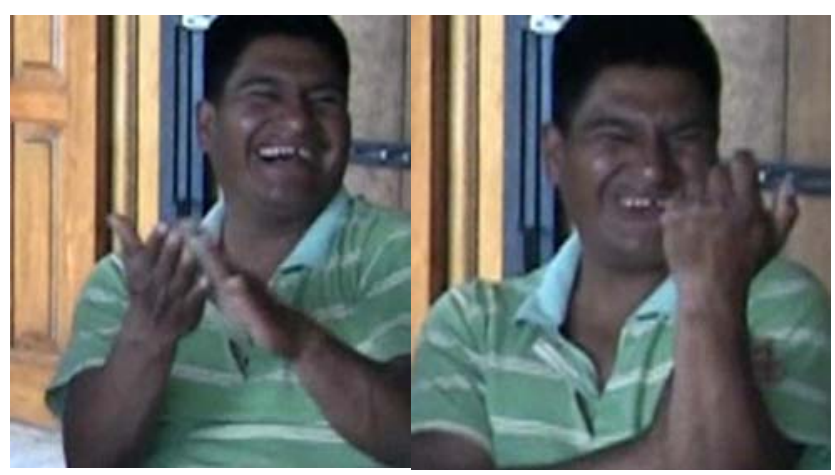

Fig. 69. Frank responding with other signs for 'money' and a laugh.

By contrast, as the brothers went on to point out, the $Z$ sign for 'cat' as they perform it is subtly different, involving the first two fingers rubbing against the thumb, sometimes with an additional puckering of the lips (Fig. 70). (The sign presumably derives from how Zinacantecs usually call cats to offer them food.)

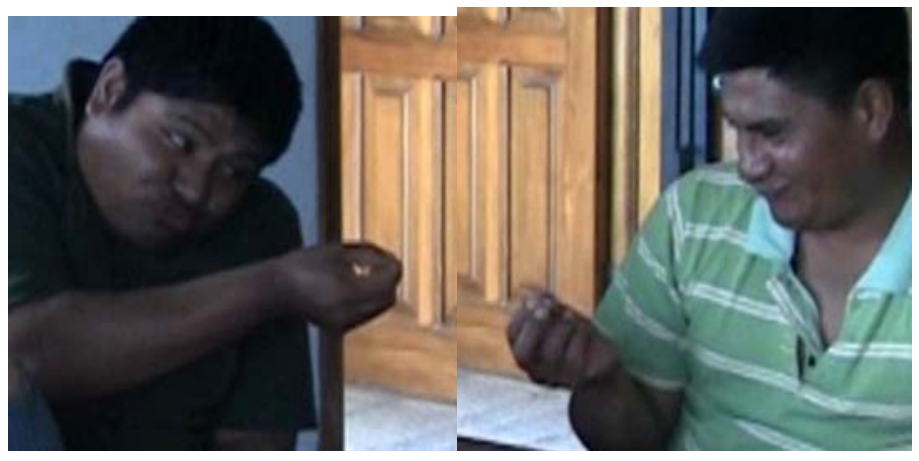

Fig. 70. The brothers performing the 'cat' sign slightly differently.

Most striking to me about this little glimpse of metalinguistic reflection is how it contrasts with the brothers' treatment of Jane with which I began this essay. Jane suffered sometimes vitriolic condemnation for mis-signing, and her brothers displayed both ridicule and at least feigned anger at her "incompetence." In this case, not only did Vic shrug his uncles' comments off-continuing to sign as he had before-but the older signers seemed unconcerned, if amused, about what might thus be viewed as a familiar example of ongoing language change (indeed, of efficient simplification). Vic could have taken from this exchange the moral that his own signing was perfectly adequate, referentially but also formally, a confirmation of his growing authority as a signer-that is, a competent, less childlike person--in his own right. This is, indeed, how languages change over generations, through small innovations that "stick" in a speech/sign community (rather than throwbacks-like Jane's chicken-that instead mark the signer as "stuck" in the past).

\section{Naked critique of referential adequacy}


I have nearly reached the end of this essay without ever explaining my title. Let me not be taken to suggest that young Vic, currently the lone fluent $2^{\text {nd }}$-generation $Z$ signer, is immune to criticism, that his signing is considered perfect, or that he has come to have an inflated sense of power and autonomy: quite the contrary. Like virtually any (Zinacantec) child his age, he is subject to merciless criticism, teasing, and scorn, about everything from how poorly he does in school, or how much it costs to feed and clothe him, to his supposed unwillingness to work around the house, share his toys with other children in the household, or even take adequate care of his own (few) possessions. His family is impoverished, and everyone knows his mother and uncles "cannot speak." He is, however, a multilingual child in a multilingual world, partitioned at home into signers vs. speakers, but more widely into Indian (indio) Tzotzil speakers and ladino (non-Indian) Spanish speakers. Only his aunt Terry, the most fluent adult hearing signer, has more communicative authority in this universe than he, and even she knows very little Spanish. His mother Jane, the original signer, sits at the other end of the autonomy scale. When criticized for her miscommunications, she is able to fight back but rarely does.

On the other hand, Vic is perfectly able to hold his own against the routine complaints about referential inadequacy inspired by the admittedly artificial picture-matching tasks I ask the signers to perform. Here is my final example, meant to suggest how well-defended and self-assured Vic can be, at the tender age of 8 , in the face of apparently forceful criticisms in which his interlocutors treat him "as an adult" for the purposes of evaluating the effectiveness of his signing performances.

Vic was describing another short animated video clip in which several protagonists (claymation sheep) were hiding with their backs against a wall around a doorway. One of the sheep peeked around the door looking for their nemesis, the cat. Vic indicated 'sheep' with his left hand on his nose, and in sequence signed 'look [around corner),' 'four sheep,' 'one sheep' (Fig. 71).

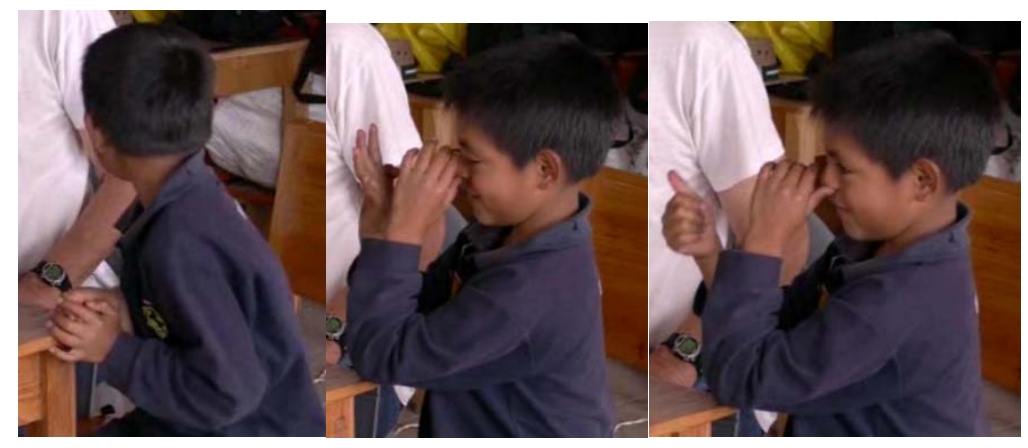

Fig. 71. Vic illustrating a scene from a video clip with sophisticated signing.

The difficulty was that Victor had seen the whole video clip, which started with four sheep with their backs to the wall, but ended with just one sheep peering around the corner. It was this single sheep pictured on the matching still frame that his uncles were meant to choose. (This 
was, of course, a glitch in my experimental design, a fault unknown to both signer and matchers.)

After the "correct" still picture had finally been found, Will launched what looked like an angry diatribe against Vic-reminiscent of that directed at Jane at the start of this essay (Fig. 22)-complaining, "But you said 'four sheep'; there's only ONE" (Fig. 72).
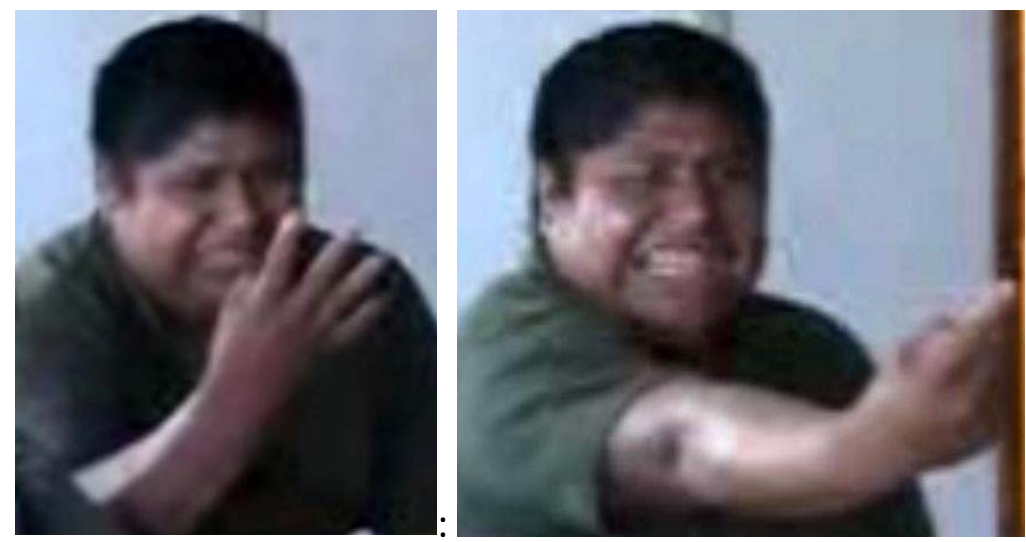

Fig. 72. Will angrily reprimanding Vic for signing the wrong number of sheep.

Without batting an eyelash, Vic defended his rendition: "There is just one: four against the wall, and one looking round the corner" (Fig. 73). His cheerful and unapologetic defense, though also grounded in his utterances' fidelity to the stimulus, contrasted dramatically with that of Jane, above (Fig. 23), in the face of parallel criticism.

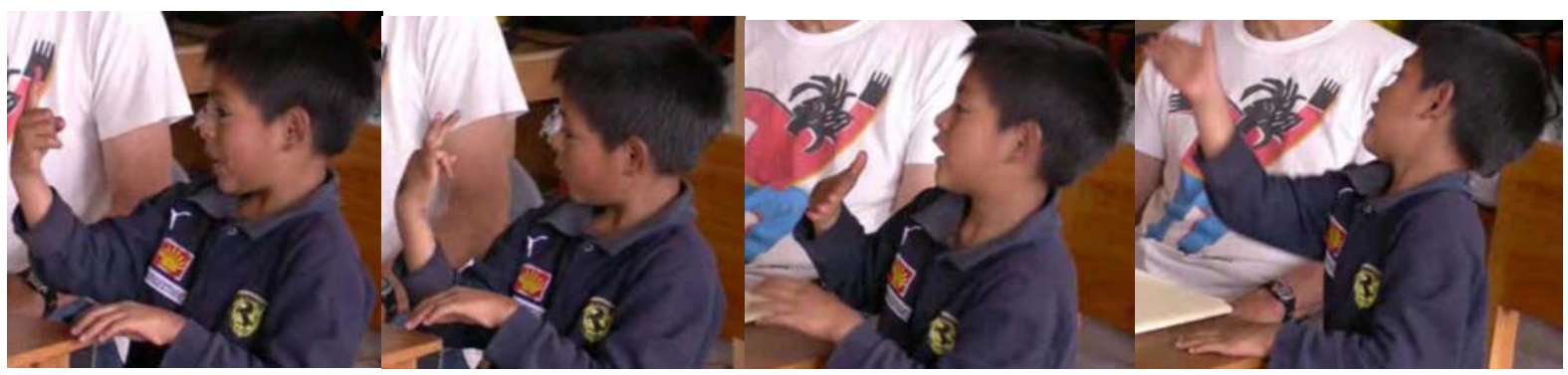

Fig. 73. Vic cheerfully defending his signing.

\section{Concluding remarks}

A young language like $Z$, which has existed for fewer than 40 years, has a radically compressed history compared to any spoken language. The evolution of its changing forms and structures can thus in principle be more neatly mapped onto the developmental time scale of human lives than can that of spoken languages which have developed over many hundreds of years, and which have in turn descended from chains of language transmission that reach even farther into the past. One thus expects to find radical changes in the structure and form of emerging sign languages in very short spans of time, with major shifts measured not by centuries but by cohorts (as they are called in, for example, young sign languages like that of Nicaragua): 
successive groups of deaf children who are introduced to a shared sign language together, and who remake it in sometimes dramatic ways that their elders can never quite catch up to (Senghas et al 2004, Senghas \& Coppola 2010). In the case of Z-very young, and also very small-the history of the language may well turn out to be virtually coextensive with the history of Jane, the first and oldest signer: $Z$ will very probably not outlive her and her brothers, or not by much, as without them there will be no deaf people for whom $Z$ is the only language available. Nonetheless, individuals enter even the short history of $Z$ at different points. They thus have radically different (sociolinguistic) biographies and consequently interact differently with the trajectory of the language and the power (or impotence) that speaking or signing confer. Partly this is a simple matter of calibrating our language scale--Z $<$ Tzotzil $<$ Spanishagainst the different life histories in play. Jane and her brothers inhabit only the $Z$ end of the scale, and the brothers make it clear that Jane's $Z$ is deficient compared to theirs. Obviously Jane depends on Z in a way that Vic does not. So, too, do Will and Frank; but for them, the growing structure of the language and its expanded expressive powers are analogues of their more expanded possibilities of movement-as men, as wage earners--in even the limited society they inhabit. The adult hearing signers, Terry and Rita, straddle both Z and Tzotzil, although Rita has learned some Spanish in school and traveled, whereas Terry-more intimately linked to the deaf signers and more constrained by her life's trajectory-has not.

Jane is trapped in her language, as she is trapped in her family and in a kind of perpetual childhood: a mother whose child is, in many ways, already her senior. Vic, born hearing into the deaf world of $Z$, was also born to breach its confines. He is a fluent signer, carefully tutored in the emerging grammar, but carefree and unbound, so far the only real member of "cohort" number two, whose trajectory propels him outwards and away. As a male, he is expected to learn Spanish and to join the wider world, spanning the entire linguistic range available in his community. He is willing to say of his mother and his uncles, pero mu $x$-a $i$ k'op, makal $x$-chikin (but NEG ASP+A3-understand language, closed A3-ear), literally "But they don't understand language; their ears are closed" - both standard Tzotzil idioms for people with whom one cannot reason. The forms of speaking/signing that crystallize his moment by moment biography free him, just as they imprison his mother.

\section{Acknowledgements:}

Thanks are due to the editors of this volume for critical comments and suggestions, especially about how to bring my own empirical materials and interests into accord with the thematic concerns of this special issue. This material is based upon work supported by the National Science Foundation under grants BCS-0935407 \& BCS-1053089, administered by the Center for Research on Language [CRL] at UCSD. Any opinions, findings, and conclusions or recommendations expressed in this material are those of the author and do not necessarily reflect the views of the National Science Foundation.

Some of the material in this essay was first presented at the inaugural conference for the Center for Language, Gesture, and Sign, Univ. of Chicago, 9 Mar. 2013, the annual meetings of the AAA, Chicago, III, Nov. 24, 2013, and at the $6^{\text {th }}$ meeting of the International Society for Gesture 
Studies, San Diego, 11 July 2014. I am indebted to suggestions from colleague on those occasions.

\section{Bibliography}

Bauman, R. 1984. Verbal art as performance. Prospect Heights, IL: Waveland Press.

Bonvillian, J. D., \& Nelson, K. E. 1976. Sign language acquisition in a mute autistic boy. Journal of Speech and Hearing Disorders 41(3), 339-347.

Cancian, F. 1965. Economics and prestige in a Maya community: The religious cargo system in Zinacantan. Stanford, CA: Stanford University Press.

Cancian, Frank. 1972. Change and uncertainty in a peasant economy: the Maya corn farmers of Zinacantan. Stanford, CA: Stanford University Press.

Cancian, F. 1994. The decline of community in Zinacantán: economy, public life, and social stratification, 19601987. Stanford, CA: Stanford University Press.

Carr, E. G., Binkoff, J. A., Kologinsky, E., \& Eddy, M. 1978. Acquisition of sign language by autistic children. I: Expressive labelling. Journal of Applied Behavior Analysis 11(4), 489.

Collier, George A. 1975. Fields of the Tzotzil: The ecological bases of tradition in highland Chiapas. Austin, TX: University of Texas Press.

Collier, J. F. 1968. Courtship and marriage in Zinacantan, Chiapas, Mexico. Middle American Research Institute, Tulane University.

Coppola, M., and A. Senghas. 2010. Deixis in an emerging sign language. In: D. Brentari (Ed.), Sign languages: A Cambridge language survey. Pp. 543-569. Cambridge: Cambridge University Press.

Folven, R. J. \& Bonvillian, J.D. 1991. The transition from nonreferential to referential language in children acquiring American Sign Language. Developmental Psychology 27, 806-816.

Fouts, R. S. 1972. Use of guidance in teaching sign language to a chimpanzee (Pan troglodytes). Journal of Comparative and Physiological Psychology, 80(3), 515.

Fulwiler, R. L., \& Fouts, R. S. 1976. Acquisition of American Sign Language by a noncommunicating autistic child. Journal of Autism and Childhood Schizophrenia, 6(1), 43-51.

Gal, Susan and Judith T. Irvine 2000. Language ideology and linguistic differentiation. In: Paul Kroskrity (Ed.), Regimes of language: ideologies, polities, and identities. Pp. 35-84. Santa Fe, NM: School of American Research Press.

Goldin-Meadow, Susan. 2003. The resilience of language: what gesture creation in deaf children can tell us about how all children learn language. New York: Psychology Press.

Grice, H. P. 1957. Meaning. The philosophical review, 377-388.

Haviland, J. B. 1977. Gossip, reputation, and knowledge in Zinacantan. Chicago: University of Chicago Press.

Haviland, J. B. 2013. (Mis)understanding and obtuseness: "Ethnolinguistic borders" in a miniscule speech community. Journal of Linguistic Anthropology 23(3), 160-191.

Haviland, J. B. 2014. Different strokes: gesture phrases and gesture units in a family homesign from Chiapas, Mexico. In: Mandana Seyfeddinipur \& Marianne Gulberg (Eds.), From gesture in conversation to visible action as utterance. Pp. 245-288. Amsterdam: John Benjamins.

Haviland, J. B. 2015. "Hey!" Topics in Cognitive Science 7 (2015), 124-149.

Haviland, J. B. (ed.) 2015b. Where do nouns come from? Edited by John B. Haviland. Benjamins Current Topics \#70. Amsterdam: John Benjamins.

Laughlin, R. M. 1975. The great Tzotzil dictionary of San Lorenzo Zinacantan. Washington, D.C.: Smithsonian Contributions to Anthropology, No. 19.

Maestas y Moores, J. 1980. Early linguistic environment: Interactions of deaf parents with their infants. Sign Language Studies, 26(1), 1-13.

Morford, J. P., \& Goldin-Meadow, S. 1997. From here and now to there and then: The development of displaced reference in homesign and English. Child Development, 68(3), 420-435.

Orlansky, M. D., \& Bonvillian, J. D. 1985. Sign language acquisition: Language development in children of deaf parents and implications for other populations. Merrill-Palmer Quarterly (1982-), 127-143.

Petitto, L. A. 1990. The transition from gesture to symbol in American Sign Language. In: V. Volterra \& C.J. Erting (Eds.), From gesture to language in hearing and deaf children. Pp. 153-161. Berlin: Springer-Verlag. 
Senghas, A. 2003. Intergenerational influence and ontogenetic development in the emergence of spatial grammar in Nicaraguan Sign Language. Cognitive Development, 18, 511-531

Senghas, A., S. Kita, and A. Özyürek. 2004. Children creating core properties of language: evidence from an emerging sign language in Nicaragua. Science, 305, 5691, 1779-1782.

Senghas, A., and M. Coppola. 2010. Getting to the point: How a simple gesture became a linguistic element in Nicaraguan signing. In: D.J. Napoli and G. Mathur (Eds.), Deaf around the world. Oxford: Oxford University Press.

Vogt, E. Z. 1969. Zinacantan: A Maya community in the highlands of Chiapas. Cambridge: Belknap Press.

Vogt, E. Z. 1976. Tortillas for the gods: A symbolic analysis of Zinacanteco rituals. Cambridge, MA: Harvard University Press. 